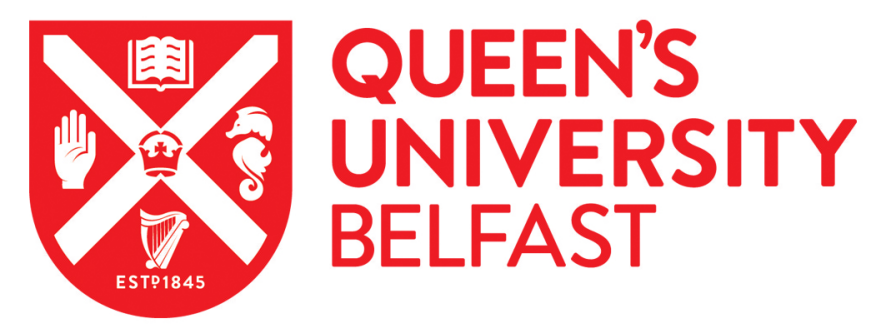

\title{
Enhancement of Wear and Corrosion Resistance of Beta Titanium Alloy by Laser Gas Alloying with Nitrogen
}

Chan, C. W., Lee, S., Smith, G., Sarri, G., Ng, C-H., Sharba, A., \& Man, H-C. (2016). Enhancement of Wear and Corrosion Resistance of Beta Titanium Alloy by Laser Gas Alloying with Nitrogen. Applied Surface Science, 367, 80-90. https://doi.org/10.1016/j.apsusc.2016.01.091

Published in:

Applied Surface Science

Document Version:

Peer reviewed version

Queen's University Belfast - Research Portal:

Link to publication record in Queen's University Belfast Research Portal

Publisher rights

(C) 2016, Elsevier

This manuscript version is made available under the CC-BY-NC-ND 4.0 license (http://creativecommons.org/licenses/by-nc-nd/4.0/), which permits distribution and reproduction for non-commercial purposes, provided the author and source are cited.

\section{General rights}

Copyright for the publications made accessible via the Queen's University Belfast Research Portal is retained by the author(s) and / or other copyright owners and it is a condition of accessing these publications that users recognise and abide by the legal requirements associated with these rights.

Take down policy

The Research Portal is Queen's institutional repository that provides access to Queen's research output. Every effort has been made to ensure that content in the Research Portal does not infringe any person's rights, or applicable UK laws. If you discover content in the Research Portal that you believe breaches copyright or violates any law, please contact openaccess@qub.ac.uk. 


\title{
Enhancement of Wear and Corrosion Resistance of Beta Titanium Alloy by Laser Gas Alloying with Nitrogen
}

\author{
Chi-Wai Chan ${ }^{1}$, Seunghwan Lee ${ }^{2}$, Graham Smith ${ }^{3}$, Gianluca Sarri ${ }^{4}$, Chi-Ho Ng ${ }^{1,5}$, Ahmed Sharba ${ }^{4}$, \\ Hau-Chung Man ${ }^{6}$
}

\author{
1 School of Mechanical and Aerospace Engineering, Queen's University Belfast, BT9 5AH, UK \\ 2 Department of Mechanical Engineering, Technical University of Denmark, DK-2800 Kgs. Lyngby, Denmark \\ 3 Department of Natural Sciences, University of Chester, Thornton Science Park, Chester, CH2 4NU, UK \\ 4 School of Mathematics and Physics, Queen's University Belfast, Belfast BT7 1NN, UK \\ 5 Laser Engineering and Manufacturing Research Centre, Faculty of Science and Engineering, University of Chester, Thornton Science \\ park, Chester CH1 4BJ, UK \\ 6 Department of Industrial and Systems Engineering, Faculty of Engineering, The Hong Kong Polytechnic University, Hong Kong, China
}

Corresponding Author: c.w.chan@qub.ac.uk

\begin{abstract}
The relatively high elastic modulus coupled with the presence of toxic vanadium (V) in Ti6Al4V alloy has long been a concern in orthopaedic applications. To solve the problem, a variety of non-toxic and low modulus beta-titanium (beta-Ti) alloys have been developed. Among the beta-Ti alloy family, the quaternary Ti-Nb-Zr-Ta (TNZT) alloys have received the highest attention as a promising replacement for Ti6AI4V due to their lower elastic modulus and outstanding long term stability against corrosion in biological environments. However, the inferior wear resistance of TNZT is still a problem that must be resolved before commercialising in the orthopaedic market. In this work, a newly-developed laser surface treatment technique was employed to improve the surface properties of Ti-35.3Nb-7.3Zr5.7Ta alloy. The surface structure and composition of the laser-treated TNZT surface were examined by grazing incidence $x$-ray diffraction (GI-XRD) and x-ray photoelectron spectroscopy (XPS). The wear and corrosion resistance were evaluated by pin-on-plate sliding test and anodic polarisation test in Hanks' solution. The experimental results were compared with the untreated (or base) TNZT material. The research findings showed that the laser surface treatment technique reported in this work can effectively improve the wear and corrosion resistance of TNZT.
\end{abstract}

Keywords: Laser Surface Treatment, Beta Titanium, TNZT, Wear, Corrosion, Surface Hardening

\section{Introduction}

Ti6Al4V alloys have long been considered as the workhorse in orthopaedic applications due to their excellent mechanical properties and corrosion resistance. However, their elastic modulus is still larger than that of human bone causing the problem of "stress-shielding" or osteopenia. The stress shielding effect which originates from the disparity of elastic modulus between implant materials and human bones causes a reduction in bone density and results in the loosening of implants in the long term [1]. Moreover, the presence of the toxic vanadium (V) element in the Ti6Al4V alloy also creates the concern of toxic ion release near the implanted area [2]. Recently, advances in materials technology have led to the development of beta-titanium (beta-Ti) alloys. Beta-Ti alloys possess desirable properties over the conventional Ti6Al4V alloy, such as lower elastic modulus, super-elastic behaviours, and no concern of toxicity/allergy problems [3]. A variety of beta-Ti alloy systems constituted by different combinations of non-allergic/toxic beta-stabilising elements ( $\mathrm{Zr}, \mathrm{Nb}, \mathrm{Ta}, \mathrm{Mo}$, $\mathrm{Fe}$, etc.) have been developed. Among them, the quaternary Ti-Nb-Zr-Ta (TNZT) alloy has received the highest attention because of its lowest Young's modulus (around $60 \mathrm{GPa}$ ) and outstanding long term stability against corrosion in biological environments $[4,5,6]$. The alloying elements in TNZT, such as 
titanium ( $\mathrm{Ti})$, niobium ( $\mathrm{Nb}$ ), zirconium $(\mathrm{Zr})$ and tantalum ( $\mathrm{Ta}$ ) exhibit excellent biocompatibility because they belong to the loose connection vascularized group with regards to tissue reaction [7]. $\mathrm{Ti}$, $\mathrm{Nb}, \mathrm{Zr}$ and $\mathrm{Ta}$ also have a considerably superior corrosion resistance due to the resultant surface oxides, such as $\mathrm{TiO}_{2}, \mathrm{Nb}_{2} \mathrm{O}_{5}, \mathrm{ZrO}_{2}$, and $\mathrm{Ta}_{2} \mathrm{O}_{5}[8]$

Two practical considerations have to be taken into account when using the TNZT alloy in load-bearings in orthopaedic applications, particularly for the metallic femoral head, i.e. hemispherical ball joint. Firstly, the ball joint surface should be highly wear-resistant to minimise the formation of wear debris during the continuous dynamic movement between the socket and ball joint in real-life service. One way to achieve this is to increase the surface hardness. Secondly, the implant surface needs to be highly corrosion-resistant, as the surface comes in direct contact with different kinds of corrosive body fluids. More importantly, the crevice between the ball joint and the socket can be the weak point to initiate the corrosion attack. On account of this, proper surface treatment to form a very hard and corrosion resistant coating on the substrate can reduce the chance of implant failure due to corrosion attack or the combined effect of corrosion and wear. In the present investigation, we report on a newly-developed laser surface treatment method, namely laser gas alloying via solid state diffusion [9], to form a smooth and hard layer on the beta TNZT alloy The wear and corrosion properties of the laser-treated surface were examined in detail and compared with those of the base TNZT material, showing significant improvement.

It is necessary to note that the TNZT alloy is a relatively new alloy system, and hence not much work has been done to investigate surface treatment to enhance the wear and corrosion properties. The existing studies in the literature can be split into three streams, namely (1) heat treatment to modify the microstructure and hence to improve the mechanical/functional properties $[10,11,12,13,14]$, (2) laser 3D printing to control the structural architecture and composition $[15,16,17,18,19]$ and (3) surface treatment to improve the bioactivity $[19,20,21,22,23,24,25,26,27]$. Few attempts on surface hardening of TNZT alloy, namely conventional gas nitriding in furnace, have been made in the literature $[28,29]$. The surface hardening of TNZT alloy by laser technology in this work is believed to be one of the first attempts of its kind. Laser technology has the competitive advantages of short treatment time, non-contact, easy control of process parameters, clean and accurate in comparison with other surface technologies. Moreover, the laser can selectively treat at specific area with high precision and as there is a metallurgical bond between the treated layer and the substrate that there is no concern of delamination/peel off at the interface.

The main objective of this work is to investigate the application of laser gas alloying treatment to improve the surface properties of TNZT via solid-state diffusion. Such a solid-state diffusion treatment has been successfully applied to improve the hardness and wear-resistance of Ti6Al4V alloy [9]. The state-of-the-art of our reported laser technique lies in the delicate control of some interrelated laser parameters, namely, laser power, workpiece scanning speed, focus position and $\mathrm{N}_{2}$ atmosphere. Among the laser parameters, the laser power, workpiece scanning speed, and focus position can be considered as laser energy input to the substrate. If the laser energy input is too high, the surface will be melt out and the pre-manufactured precise surface finishing on the femoral head implant will be destroyed. On the contrary, if the laser energy input is too low, the surface layer will not be thick enough to serve as a barrier to protect the femoral head implant from corrosion, wear and a combination of both. Taking all this into consideration, the laser parameters were carefully chosen from a preliminary screening study [30]. The results of the preliminary study, such as nano-indentation test, 3D profile and contact angle measurements, are summarised in Table 1. The image of the lasertreated surface obtained in the preliminary study is shown in Figure 1. 


\section{Experimental Methods}

\subsection{Materials}

The material was a $250 \mathrm{~mm} \times 250 \mathrm{~mm} \times 3 \mathrm{~mm}$ Ti-35.3Nb-7.3Zr-5.7Ta (TNZT) flat plate purchased from American Element, USA. It was cut into $40 \mathrm{~mm} \times 30 \mathrm{~mm}$ for experimentation. The chemical composition of the material is depicted in Table 2. Before the laser experimentation, the sample surface was ground by a series of sandpapers from 240 to 800 grit following the standard procedure to ensure surface consistency. The roughness $(\mathrm{Ra})$ of the sample after grinding was between 140 and $190 \mathrm{~nm}$ (Table 1). Then the samples were cleaned and degreased ultrasonically in methanol for 10 $\mathrm{min}$, rinsed in distilled water for another $10 \mathrm{~min}$, and dried thoroughly in cold air stream.

\subsection{Laser Surface Treatment}

The laser surface treatment process was performed using a continuous wave (CW) 100W fiber laser (SPI Lasers UK Ltd, UK). The wavelength of the laser is $1091 \mathrm{~nm}$. After cleaning with methanol and drying in air, the samples were irradiated with the fiber laser using the following processing parameters: laser power $=25 \mathrm{~W}$, workpiece scanning speed $=1 \mathrm{~mm} / \mathrm{s}$, focus position: $10 \mathrm{~mm}$ away from the nozzle tip (or laser spot size of $1.1 \mathrm{~mm}$ ), overlap neighbouring tracks: $0.3 \mathrm{~mm}$ (or overlapping ratio of $28 \%$ ), shielding gas type: high purity nitrogen, gas flow rate: $30 \mathrm{~L} / \mathrm{min}$ for constructing a uniform and defect-free surface layer. The $\mathrm{N}_{2}$ gas was delivered to the laser-irradiated area via central and side gas jets. The experimental setup is shown in the schematic diagram in Figure 2.

\subsection{Surface Microstructure and Composition Characterization}

The phases present in the treated and untreated surfaces were identified using X-ray diffraction (XRD, D8 Advance, Bruker) at $40 \mathrm{kV}$ and $25 \mathrm{~mA}$ using $\mathrm{Cu} \mathrm{K \alpha}$ radiation with a scanning rate of $1^{\circ} \mathrm{min}^{-1}$. To avoid spurious signal coming from the substrate, grazing incidence X-Ray diffraction (GI-XRD) was used to characterise the surface structure of the thin laser-formed layer. GI-XRD was carried out with the diffraction angle varying between $20^{\circ}$ and $80^{\circ}$, and an incident angle of $10^{\circ}$ to give the most recognizable pattern to determine the phase. The selection was based on a number of preliminary tests with different incident angles varying between $0.5^{\circ}$ and $25^{\circ}$. The penetration depth of $\mathrm{Cu} \mathrm{K \alpha}$ radiation in Ti is estimated at approximately $11 \mu \mathrm{m}$, and may be expected to be lower in the TNZT alloy due to the higher density, and so at $10^{\circ}$ incidence the information depth is less than approximately $2 \mu \mathrm{m}$.

The cross-sectional microstructure of the laser-treated sample was characterized by scanning-electron microscopy (SEM, JSM-6490, JEOL). The cross-sectioned sample for SEM were polished with $1 \mu \mathrm{m}$ diamond paste and then etched using $10 \% \mathrm{HF}+40 \% \mathrm{HNO}_{3}+50 \% \mathrm{H}_{2} \mathrm{O}$ for 20 seconds.

X-ray photoelectron spectroscopy (XPS) was performed to study the chemical composition of the surfaces. Spectra were acquired using a bespoke ultra-high vacuum system fitted with a Specs $\mathrm{GmbH}$ Focus 500 monochromated Al Ka X-ray source, a Specs $\mathrm{GmbH}$ Phoibos $150 \mathrm{~mm}$ mean radius hemispherical analyser with 9-channeltron detection, and a Specs GmbH FG20 charge neutralising electron gun. The survey and narrow scans were acquired over the binding energy range between 0 and $1100 \mathrm{eV}$ using a pass energy of $50 \mathrm{eV}$ and the high resolution scans were made over individual photoelectron lines using a pass energy of $15 \mathrm{eV}$. Data processing and curve fitting were carried out using the CasaXPS software v2.3.16.

\subsection{Wear Test}

The coupling of ultra-high-molecular-weight polyethylene (UHMWPE) and Ti6AI4V represents the bearing pair challenged in orthopaedic implants, i.e. plastic acetabular cup against metallic femoral ball head [31]. Thus, the evaluation of the wear behaviour of TNZT against UHMWPE is an important 
criterion to determine the long-term performance and safety of the implants. In this study, a reciprocating wear test was employed to evaluate the wear properties of the laser-treated and untreated surfaces against UHMWPE. This was carried out by using a pin-on-plate sliding machine (TE99 Universal Wear Machine, Phoenix Tribology).

In the reciprocating wear test, an $8 \mathrm{~mm}$ diameter flat-ended UHMWPE pin was fixed in the sliding carriage. It was clamped and pressed endwise against the counter-face metallic plates, namely the laser-treated and untreated surfaces. A normal load of $50 \mathrm{~N}$ (or applied stress of $1 \mathrm{MPa}$ ) was chosen. The frequency was $1 \mathrm{~Hz}$ and the stroke length was $30 \mathrm{~mm}$ for test duration of 43200 cycles (about 2.5 $\mathrm{km}$ of sliding distance) in Hanks' solution (See Table 3 for the composition) at room temperature. The wear resistance was evaluated using the wear factor calculated by the Archard equation [32]:

$$
k_{i}=\frac{V_{i}}{F \times s}
$$

Where $F$ is the normal load $(N), s$ is the sliding distance $(m), V_{i}$ is the wear volume $\left(\mathrm{mm}^{3}\right)$ and $k_{i}$ is the wear factor (or the specific wear rate coefficient) $\left(\mathrm{mm}^{3} / \mathrm{Nm}\right)$. Index i identifies the surface considered.

The wear factors for the laser-treated and untreated surfaces were determined, and the results were taken from the average of four repetitive tests. The average of the four replicas along with the standard deviation are plotted for comparison between the two surfaces. The wear marks left on the surfaces after the wear tests were captured by a 3D optical measurement system (Wyko NT8000, Veeco Instruments). The set-up parameters for the 3D profile measurement are given as follows: size $=2543 \times 2543$ and sampling $=198.17 \mathrm{~nm}$.

\subsection{Corrosion Test}

Anodic polarization tests were carried out to evaluate the corrosion properties of the laser-treated and untreated surfaces. The polarization tests were conforming to ASTM Standard G5-94 [33]. A potentiostat (Model 273A, M352 software, EG \& G Princeton Applied Research) with a standard threeelectrode system was used. The test medium was Hanks' solution at $37^{\circ} \mathrm{C}$ and with $\mathrm{pH}$ value 7.4. The temperature was controlled by immersing the corrosion cell in a temperature-controlled water bath. A pair of graphite rods were used as counter electrodes. The reference electrode was a saturated calomel electrode (SCE). Both the laser-treated and untreated samples were cut into $15 \mathrm{~mm}$ diameter circular shape by EDM wire cutting machine. The circular samples were then fitted into a standard sample holder with the surface area exposed to the test medium controlled as $1 \mathrm{~cm}^{2}$. The tests were started after an initial delay of $60 \mathrm{~min}$ in order to achieve an equilibrium state (or a stable OCP) between the sample surface and test medium. The starting point was $200 \mathrm{mV}$ below the open-circuit potential (OCP) and the scanning rate was $0.5 \mathrm{mV} / \mathrm{s}$. The polarization tests were repeated three times for each sample to enable the reproducibility of test results. 


\section{Results and Discussions}

\subsection{Surface Structure (SEM and GI-XRD)}

The SEM micrograph in Figure 3 shows that the thickness of the surface layer (with brighter white colour) was within the range of $500 \mathrm{~nm}$ to $1 \mu \mathrm{m}$. Further, a distinctive diffusion zone can be clearly observed beneath the surface layer. It is necessary to note that the surface structure of the laserformed layer on TNZT surface cannot be characterised by classical theta-2 theta approach because the $X$-ray can penetrate through the thin layer and hit the substrate underneath. The resultant XRD pattern will be dominated by response from the substrate rather than the laser-formed layer which is of interest. On account of this, GI-XRD was chosen to characterise the surface structure of the lasertreated surface.

The GI-XRD patterns of the laser-treated and untreated surfaces at $10^{\circ}$ incidence angle are shown in Figure 4. As observed, the (110) peak at approximately $38.5^{\circ}$ diffraction angle clearly indicated the presence of bcc beta phase in both surfaces. The untreated TNZT surface (red line in Figure 4) exhibited only the bcc $\beta$ phase, as shown by the presence of the (110) and (211) peaks. No alpha phase was detected. This is due to the presence of beta stabilizing elements ( $\mathrm{Nb}, \mathrm{Zr}$ and $\mathrm{Nb}$ ) in the material which suppresses the formation of alpha phase. In comparison, the XRD pattern of laser-treated TNZT surface (blue line in Figure 4) showed that the (110) peak intensity significantly increased and a distinctive (200) peak at was found in the pattern. When carefully examining the region around the (110) peak (see the inset in Figure 4), a small (101) peak was found, indicating the presence of the alpha phase. The precipitation of alpha phase in the laser-formed layer is believed to be one of the reasons for the enhancement of surface hardness as observed in Table 1.

The surface structure of the laser-treated TNZT cannot be straightforwardly explained because of the competing nature between the beta stabilizing phases ( $\mathrm{Ta}, \mathrm{Nb}$ and $\mathrm{Zr}$ ) and the alpha stabilizing effects of nitrogen [34]. A recent study by Mohseni et al. [34] suggested a possible phase formation sequence for the laser-deposited TNZT alloy in nitrogen atmosphere. After melting, TiN precipitates will firstly form in the liquid phase and act as a nucleation sites for beta grains during solidification. On subsequent cooling, the retained nitrogen in the beta grains will facilitate the precipitation of alpha phase. This, in turn, indicates that the precipitation of alpha phase is due to the alpha stabilizing effects of nitrogen.

Due to the thermodynamically favourable interactions between $\mathrm{Ti}$ and $\mathrm{N}_{2}$ atmosphere during thermal processing [34] [35] titanium nitride (TiN) should be present in the laser-treated TNZT surface. Although a comprehensive GI-XRD measurement (incident angles varying between $0.5^{\circ}$ and $25^{\circ}$ ) was conducted on the laser-treated surface, the results cannot reveal the presence of TiN. It is possibly because the laser surface treatment process was performed in comparatively low temperature regime at which no surface melting occurred. The nitride formed by solid-state diffusion in TNZT might not be easily detected by the GI-XRD measurement. However, the presence of alpha phase and diffusion zone beneath the surface layer (Figure 3 ) as well as the golden yellow surface (Figure 1) and significant increase of surface hardness (Table 1) still give some clues to indicate that TiN is present in the laserformed layer. Still, more in-depth microstructure analysis is needed to confirm about this.

\subsection{Wear Test (Pin-on-plate Sliding Test)}

Figure 5 shows the wear factors obtained from the sliding contacts of UHMWPE pin against the lasertreated or untreated TNZT surfaces. In general, the wear factors are lower after the laser surface treatment for the overall tribosystem, and yet this trend is clearer for UHMWPE pins than TNZT plates. For the case of TNZT, the wear factor decreased by ca. $26 \%$ on average after the laser surface treatment, but the overlapped error bars appear to blur the improvement of the wear resistant 
properties by the laser surface treatment. Nevertheless, this is mainly due to the high level of scatter in the wear factor data of the untreated TNZT samples. Much smaller variations in the wear factors of the laser treated TNZT samples imply that the wear properties of TNZT became more stabilized and reproducible by the surface treatment. Moreover, wear grooves along the sliding tracks as revealed by the 3D profile images shown in Figure 6 are clearly visible only from the untreated TNZT plates after the wear tests, which support the improvement in the anti-wear properties of TNZT samples by the laser treatment. This can be ascribed to the formation of a hard surface layer on top of the TNZT surface and consequent improvement in their mechanical properties [30]. The roughness parameters extracted from the 3D profile images (Figure 6) are given in Table 4.

For the case of UHMWPE, the reduction in the wear factors by the laser treatment (ca. $27 \%$ on average) is even more evident. This can be firstly linked to the improved wear resistant properties of the counter surface, namely TNZT, by the laser treatment, especially if three body abrasive wear was the dominant wear mode: Since UHMWPE is softer than TNZT, wear of TNZT surface can occur predominantly by TNZT wear particles as third body even though some protruded asperities on TNZT surface can be initially removed by UHMWPE surface. Previous tribological studies of Ti-based alloys, such as $\mathrm{Cp} \mathrm{Ti}$ [36] or Ti6AI4V [37, 38, 39], sliding against UHMWPE surfaces have also shown reduction in the wear volumes of UHMWPE, as a result of various surface treatments of Ti-based metallic materials, such as ion implantation [36, 37, 38, 39], thermal oxidation [37, 39], or oxygen diffusion [37]. While detailed mechanisms are different for each case, a common factor related to the improved anti-wear properties in those studies is the formation of hard surface layer and the improvement in water wettability of Ti-based materials [36, 37, 38, 39]. Consequently, improved water lubrication leads to the reduced friction and wear of the tribological interface, i.e. not only titanium metallic surface, but also UHMWPE. As reported in a previous study [30], improved water wettability of the laser-treated TNZT samples (static water contact angle from ca. $66^{\circ}$ to $55^{\circ}$ ) is also evident as a result of oxide film formed on the surface (see the section 3.4 for details) and is mainly responsible for the reduced wear factor of UHMWPE.

It is also interesting to note that the wear factors of UHMWPE are somewhat lower than those of TNZT for both untreated and laser-treated samples (Figure 5). In view of abrasive wear mechanisms, this behaviour might be puzzling at a first glance as the hardness of TNZT is substantially higher than that of UHMWPE, and abrasive wear is expected to occur mainly on the softer side of the tribopair, i.e. UHMWPE in this study. Wear of titanium-based metallic materials in sliding against UHMWPE has, however, been reported in many earlier studies [36, 37, 38, 39], even though a direct quantitative comparison of the wear of UHMWPE vs metallic components is rare to date. One possible explanation is that initially generated wear debris from TNZT surface may be embedded on the softer UHMWPE side and act as abrasive grits against TNZT surfaces [37] as UHMWPE wear debris can hardly wear off TNZT surfaces. Due to low contact pressure applied in this study, ca. $1 \mathrm{MPa}$, adhesive wear is not considered as a major wear mode. Although the wear test was conducted in Hanks' solution which contains $\mathrm{Cl}$ - ions and can induce pitting attack to the metal surface, no pitting was found from both the laser-treated and untreated surfaces after wear tests. There were no signs of corrosive wear. Overall, the experimental results in the work are in agreement with the speculation made in the previous study [30] that the increased surface hardness from the laser-formed hard layer is ultimately responsible for the improved wear resistance of the tribopair composed of TNZT and UHMWPE.

\subsection{Corrosion Test (Anodic Polarisation Test)}

The corrosion resistance of the laser-treated and untreated TNZT surfaces was evaluated by anodic polarization tests in Hank's solution at $37^{\circ} \mathrm{C}$, and the results are depicted by the polarization curves in Figure 7. The corrosion parameters extracted from the curves are shown in Table 5. It could be 
observed that the polarisation curve of the laser-treated surface obviously shifted to the left in Figure 7 and the curve also positioned higher than that of the untreated surface. This indicated that the lasertreated surface had a higher corrosion resistance given the higher open-circuit potential (OCP) and smaller current density values. The current density was at least one order of magnitude smaller than the untreated surface. The improved corrosion resistance of the laser-treated surface could be attributed to the presence of the inert and passive oxide film on the laser-formed layer. To verify this hypothesis, surface XPS analysis was carried out to characterise the chemical composition and structure of the oxide film. A comparison was made between the laser-treated and untreated TNZT surfaces. The results are shown and discussed in detail in the section 3.4.

It is to note that no pitting was identified in both curves, and this observation reinforced the argument in the wear test section that corrosion wear was not a major mechanism contributed to the loss of materials for both laser-treated and untreated surfaces. Hanks' solution is a commonly used medium in corrosion tests for bio-implant materials [40]. The absence of pitting attack after testing in Hanks' solution showed that both the laser-treated and untreated TNZT surfaces exhibited excellent resistance to localised corrosion, and can be used in applications where pitting corrosion is a concern. It has been previously reported that the presence of niobium and zirconium oxides in passive $\mathrm{TiO}_{2}$ film can reduce the $\mathrm{Cl}^{-}$ingress into the oxide film and increase its structural integrity, and thus, pit initiation events are reduced $[41,42]$.

\subsection{Surface Composition (XPS)}

It is believed that the outstanding corrosion resistance measured in the polarisation tests was due to the formation of protective oxide film on the metal surface in an oxidizing medium, such as Hanks' solution. However, the surface oxide film is normally amorphous or of low crystallinity and is very thin, namely in range of a few nanometres, and hence it is very difficult to detect by techniques such as EDS and XRD. In this work, the surface-sensitive analytical technique of XPS was used to study the oxide film in order to build up a thorough understanding of the chemical composition and structure of the topmost surface layer. XPS survey and narrow scans were carried out on the laser-treated and untreated TNZT surfaces, and the scans were done at the outermost surface (without sputter cleaning), i.e. at $0 \AA$ depth. The XPS survey scan spectrum (in Figure 8 ) showed that, apart from the presence of the expected key elements $(\mathrm{Ti}, \mathrm{Nb}, \mathrm{Zr}, \mathrm{Ta}, \mathrm{O}$ and $\mathrm{N})$, both laser-treated and untreated surfaces revealed the presence of carbon $(C)$ in the form of hydrocarbons. It is believed that carbon was present as a contamination from environment or cleaning process. The XPS compositional measurements for the laser-treated and untreated outermost surface layers are given in Table 6.

Figure 9(a-h) show the XPS spectra of different elements obtained from narrow scans over the Ti 2p, $\mathrm{Nb} 3 \mathrm{~d}, \mathrm{Zr} 3 \mathrm{~d}, \mathrm{Ta} 4 \mathrm{f}$, and $\mathrm{O}$ 1s lines for the laser-treated and untreated TNZT samples. The curve fits to the data were made with line-shapes, doublet separations and doublet intensities constrained to known reference values for the chemical states indicated in Figure 9. The Ti $2 p$ XPS spectra of the untreated surface (Figure 9a) showed that while the outermost oxide layer contained mainly the $\mathrm{TiO}_{2}$ (or $\mathrm{Ti}^{4+}$ ), small amounts of sub-oxides ( $\mathrm{TiO}$ or $\mathrm{Ti}^{2+}, \mathrm{Ti}_{2} \mathrm{O}_{3}$ or $\mathrm{Ti}^{3+}$ ) and some metallic $\mathrm{Ti}$ were also found. In comparison, the outermost oxide layer on the laser-treated surface (Figure 9b) was purely made up of $\mathrm{TiO}_{2}$ and no other sub-oxides were detected in the oxide film. This indicates that heating by laser radiation is sufficiently effective to drive a complete oxidation of $\mathrm{Ti}_{\text {into }} \mathrm{Ti}^{4+}$ on the TNZT surface. Similar observations can be found from the spectra of other alloying elements: $\mathrm{Nb} 3 \mathrm{~d}$ (Figure $7 \mathrm{~d}$ ), $\mathrm{Zr}$ 3d (Figure 9f), and Ta $4 f$ (Figure 9h). A complete oxidation of these elements was found in the outermost oxide layer on the laser-treated surface, and no other sub-oxides were detected. In contrast, the $\mathrm{Nb} 3 \mathrm{~d}, \mathrm{Zr} 3 \mathrm{~d}$ and $\mathrm{Ta} 4 \mathrm{f}$ spectra from the untreated surface showed incomplete oxidation 
with small amounts of sub-oxides present in the outermost layer. A summary of different oxides detected in the outmost oxide layers on the laser-treated and untreated surfaces is given in Table 7.

The findings in the XPS analysis indicated that the corrosion resistance of TNZT originated from the spontaneous formation of $\mathrm{TiO}_{2}$-based passive oxide on the surface. Further, a more protective oxide film can be obtained by laser surface treatment due to (i) complete oxidation of the alloying elements, particularly $\mathrm{Ti}$ into $\mathrm{TiO}_{2}$ and $\mathrm{Nb}$ into $\mathrm{Nb}_{2} \mathrm{O}_{5}$, (ii) higher concentration of $\mathrm{Ti}$ and $\mathrm{O}$ and (iii) absence of titanium sub-oxides, such as $\mathrm{Ti}_{2} \mathrm{O}_{3}$, in the outermost oxide film.

First, $\mathrm{TiO}_{2}$ and $\mathrm{Nb}_{2} \mathrm{O}_{5}$, as products of the complete oxidation, are well known for their extremely high corrosion resistance and thermodynamic stability [8]. Second, the quantitative compositional results (in Table 6) indicate that the oxide film is enriched with more Ti and $\mathrm{O}$ after laser surface treatment, i.e. the concentration of Ti and $O$ in the outermost surface layer increased from 7.59 to 10.43 at.\% and from 41.81 to 48.71 at.\% respectively. This, in turn, means that higher amount of $\mathrm{TiO}_{2}$ is present in the laser-treated surface compared with the untreated surface. Third, absence of $\mathrm{Ti}^{3+}$ ions in the outermost surface layer will result in a decrease in the concentration of anion vacancies in the $\mathrm{TiO}_{2}$ crystal lattice, leading to the formation of less defective oxide film [43,44]. Although the oxide film of the laser-treated surface is "less defective" but "not perfect", i.e. anion vacancies still be present. This is the reason why the laser-formed oxide film is not completely insulative for protecting substrate against corrosion.

Finally, it is important to comment on the differences between the air-passivated oxide film on the untreated surface and the laser-formed oxide film on the laser-treated surface. Saha and Tompkins [45] pointed out that the native oxide Ti $2 \mathrm{p}_{3 / 2}$ peak between $458.4 \mathrm{eV}$ and $458.6 \mathrm{eV}$ is a characteristic of amorphous $\mathrm{TiO}_{2}$ and the peak at $459.1 \mathrm{eV}$ is a characteristic of crystalline $\mathrm{TiO}_{2}$. In our XPS results, the $\mathrm{Ti} 2 \mathrm{p}_{3 / 2}$ peak of the untreated and laser-treated surfaces is located at $458.6 \mathrm{eV}$ and $458.75 \mathrm{eV}$, respectively. This provides further evidence that the oxide films are of amorphous or low-crystalline structure with the laser-formed oxide more crystalline than the air-passivated oxide. In addition, since the laser experimentation was conducted in normal laboratory conditions (not vacuum environment), the laser-irradiated area still has a chance to react with $\mathrm{O}_{2}$ from surrounding air. The calculation results from Nakai et al. [28] showed that $\mathrm{TiO}_{2}$ can be formed in the TNTZ surface in high purity nitrogen atmosphere given that a small amount of oxygen is present in the atmosphere, i.e. $1.33 \times 10^{-17}$ pa. This explained why $\mathrm{TiO}_{2}$ is found in the outermost surface of the laser-treated sample.

\subsection{Effect of Nitrogen on the Wear and Corrosion Properties}

It has been widely accepted that irradiation of Ti with laser in a $\mathrm{N}_{2}$ atmosphere can lead to a strong take-up of nitrogen into the irradiated surfaces, and thus, hard and adherent layers of TiN are formed [46]. Although the GI-XRD analysis cannot detect the TiN in the surface structure, the possibility of TiN present in the laser-formed layer cannot be ruled out, i.e. the laser treatment process was performed in the $\mathrm{N}_{2}$ atmosphere. TiN can react with oxygen or air or water to form the $\mathrm{TiO}_{2}$ film on the topmost surface [45] [47]. The oxidation of TiN can contribute to the improved corrosion property of the laserformed layer. On the other hand, the effect of nitrogen on the wear property of the laser formed layer can be ascribed to the precipitation of nitrogen-enriched alpha phase and/or TiN [34]. The explanations for the precipitation of the alpha phase have been given in the Section 3.1. Alpha phase is harder and stiffer than beta phase [48]. The recent findings by Mohseni et al. [34] indicated that the hard and stiff alpha phase has a higher resistance to interfacial shear stresses present in the sliding wear than the softer and compliant beta phase, i.e. beta phase has a higher tendency of being loose and ejected as wear particles. 
From the experimental findings, oxidation appeared to be the dominant reaction over nitriding in the laser treatment process. On account of this, the protection against the wear and corrosion could be attributed more to the laser-formed/air-passivated surface oxides than the nitrides.

\section{Conclusions}

In this study, the influence of laser surface treatment on the wear and corrosion resistance of beta Ti$\mathrm{Nb}-\mathrm{Zr}$-Ta (TNZT) alloy was studied, and the results were compared with the untreated (or base) material. To understand the mechanisms to protect the TNZT from wear and corrosion in Hanks' solution, the surface structure and composition were characterised by grazing incidence $x$-ray diffraction (GI-XRD) and x-ray photoelectron spectroscopy (XPS). The following conclusions were reached:

1. After careful selection of the laser process parameters, a smooth and uniform hard layer (between $500 \mathrm{~nm}$ and $1 \mathrm{um}$ ) was formed on the TNZT surface.

2. The GI-XRD results indicated that alpha phase was formed after laser surface treatment.

3. The laser-treated surface showed an improved wear resistance in sliding against UHMWPE in Hanks' solution, as evidenced by the smaller amount of material loss for both TNZT and UHMWPE in the pin-on-plate sliding test.

4. The laser-treated surface also exhibited a better corrosion resistance in Hanks' solution at $37^{\circ} \mathrm{C}$. This can be evidenced by the higher open-circuit potential (OCP) and small current density values in the anodic polarisation test.

5. The XPS results showed that the outermost oxide layer on the laser-formed hard layer mainly consisted of $\mathrm{TiO}_{2}$ and $\mathrm{Nb}_{2} \mathrm{O}_{5}$ which contributed to the outstanding corrosion resistance of the surface.

\section{Acknowledgment}

The work described in this paper was supported by research grants from the Hong Kong Polytechnic University (G-YK36 and G-YM75), Hong Kong Special Administration Region, China, and the Queen's University Belfast (Start-up Research Fund: D8201MAS), United Kingdom. 


\section{References}

[1] M.R. Prince, E.W. Salzman, F.J. Schoen, A.M. Palestrant, M. Simon, "Local intravascular effects of the nitinol wire blood clot filter," Invest Radiol, vol. 23, no. 4, pp. 294-300, 1988.

[2] F. Kasano, T. Morimitsu, "Utilization of nickel-titanium shape memory alloy for stapes prosthesis," Auris Nasus Larynx, vol. 24, no. 2, pp. 137-142, 1997.

[3] J. Ryhanen, M. Kallioinen, W. Serlo, P. Peramaki, J. Junila, P. Sandvik, E. Niemela, J. Tuukkanen, "Bone healing and mineralization, implant corrosion, and trace metals after nickel-titanium shape memory metal intramedullary fixation," Journal of Biomedical Materials Research, vol. 47, no. 4, pp. 472-480, 1999.

[4] Y. Okazaki, "A new Ti-15Zr-4Nb-4Ta alloy for medical applications," Current opinion in Solid State \& Materials Science, vol. 5, no. 1, pp. 45-53, 2001.

[5] Y. Tanaka, M. Nakai, T. Akahori, M. Niinomi, Y. Tsutsumi, H. Doi, T. Hanawa, "Characterization of air-formed surface oxide film on Ti-29Nb-13Ta-4.6Zr alloy surface using XPS and AES," corrosion Science, vol. 50, no. 8, pp. 2111-2116, 2008.

[6] D. Mareci, R. Chelariu, D.M. Gordin, G. Ungureanu, T. Gloriant, "Comparative corrosion study of Ti-Ta alloys for dental application," Acta Biomaterialia, vol. 5, no. 9, pp. 3625-3629, 2009.

[7] Y.L Zhou, M. Niinomi, T. Akahori, M. Nakai, H. Fukui, "Comparison of various properties between titanium-tantalum alloy and pure titanium for biomedical applications," Materials Transactions, vol. 48, no. 3, pp. 380-384, 2007.

[8] M. Khartega, V. Raman, N. Rajendran, "Influence of potential on the electrochemical behaviour of b titanium alloys in Hank's solution," Acta Biomaterialia, vol. 3, no. 6, pp. 1019-1023, 2007.

[9] H.C. Man, M. Bai, F.T. Cheng, "Laser diffusion nitriding of Ti-6Al-4V for improving hardness and wear resistance," Applied Surface Science, vol. 258, no. 1, pp. 436-441, 2011.

[10] L. M. Elias, S. G. Schneider, S. Schneider, H.M. Silva, F. Malvisi, "Microstructural and mechanical characterization of biomedical Ti-Nb-Zr(-Ta) alloys," Materials Science and Engineering: $A$, vol. 432, no. 1-2, pp. 108-112, 2006.

[11] A. Fukuda, M. Takemoto, T.Saito, S. Fujibayashi, M. Neo, S. Yamaguchi, T. Kizuki, T. Matsushita, M. Niinomi, T. Kokubo, T. Nakamura, "Bone bonding bioactivity of Ti metal and Ti-Zr-Nb-Ta alloys with $\mathrm{Ca}$ ions incorporated on their surfaces by simple chemical and heat treatment," Acta Biomaterialia, vol. 7, no. 3, pp. 1379-1386, 2011.

[12] M. Tahara, H.Y. Kim, H. Hosoda, T. Nam, S. Miyazaki, "Effect of nitrogen addition and annealing temperature on superelastic properties of Ti-Nb-Zr-Ta alloys," Materials Science and Engineering: A, vol. 527, no. 26, pp. 6844-6852, 2010.

[13] S. Nag, R. Banerjee, H.L. Fraser, "Microstructural evolution and strengthening mechanisms in Ti-Nb-Zr-Ta, Ti-Mo-Zr-Fe and Ti-15Mo biocompatible alloys," Materials Science and Engineering: C, vol. 25, no. 3, pp. 357-362, 2005. 
[14] C. R. M. Afonso, P. L. Ferrandini, A. J. Ramirez, R. Caram, "High resolution transmission electron microscopy study of the hardening mechanism through phase separation in a b-Ti-35Nb-7Zr5Ta alloy for implant applications," Acta Biomateralia, vol. 6, no. 4, pp. 1625-1629, 2010.

[15] R. Banerjee, S.Nag, H.L. Fraser, "A novel combinatorial approach to the development of beta titanium alloys for orthopaedic implants," Materials Science and Engineering: C, vol. 25, no. 3, pp. 282-289, 2005.

[16] S. Nag, R. Banerjee, H.L. Fraser, "Intra-granular alpha precipitation in Ti-Nb-Zr-Ta biomedical alloys," Journal of Material Science, vol. 44, no. 3, pp. 808-815, 2009.

[17] S. Nag, S. Samuel, A. Puthucode, R. Banerjee, , "Characterization of novel borides in Ti-Nb-ZrTa+2B metal-matrix composites," Materials Characterization, vol. 60, no. 2, pp. 106-113, 2009.

[18] S. Samuel, S. Nag, S. Nasrazadani, V. Ukirde, M. E. Bounanani, A. Mohandas, K. Nguyen, R. Banerjee, "Corrosion resistance and in vitro response of laser-deposited Ti-Nb-Zr-Ta alloys for orthopedic implant applications," Journal of Biomedical Materials Research Part A, vol. 94A, no. 4, pp. 1251-1256, 2010.

[19] S. Samuel, S. Nag, T. W. Scharf, R. Banerjee, "Wear resistance of laser-deposited boride reinforced Ti-Nb-Zr-Ta alloy composites for orthopedic implants," Materials Science \& Engineering C, vol. 28, no. 3, pp. 414-420, 2008.

[20] Y. Tsutsumi, M. Niinomi, M. Nakai, H. Tsutsumi, H. Doi, N. Nomura, T. Hanawa, "Micro-arc oxidation treatment to improve the hard-tissue compatibility of Ti-29Nb-13Ta-4.6Zr alloy," Applied Surface Science, vol. 262, pp. 34-38, 2012.

[21] S.J. Li, R. Yang, M. Niinomi, Y.L. Hao, Y.Y. Cui, "Formation and growth of calcium phosphate on the surface of oxidized Ti-29Nb-13Ta-4.6Zr alloy," Biomaterials, vol. 25, no. 13, pp. 2525$2532,2004$.

[22] T. Kasuga, M. Nogami, M. Niinomi, T. Hattori, "Bioactive calcium phosphate invert glassceramic coating on $\beta$-type Ti-29Nb-13Ta-4.6Zr alloy," Biomaterials, vol. 24, no. 2, pp. 283-290, 2003.

[23] T. Akahori, M. Niinomi, M. Nakai, H. Fukuda, H. Fukui, M. Ogawa, "Bioactive Ceramic Surface Modification of $\beta$-Type Ti-Nb-Ta-Zr System Alloy by Alkali Solution Treatment," Materials Transactions, vol. 48, no. 3, pp. 293-300, 2007.

[24] J. Hieda, M. Niinomi, M. Nakai, K. Cho, T. Gozawa, H. Katsui, R. Tu, T. Goto, "Enhancement of adhesive strength of hydroxyapatite films on Ti-29Nb-13Ta-4.6Zr by surface morphology control," Journal of the Mechanical Behavior of Biomedical Materials, vol. 18, pp. 232-239, 2013.

[25] T. Akahori, M. Niinomi, M. Nakai, T. Kasuga, M. Ogawa, "Characteristics of Biomedical BetaType Titanium Alloy Subjected to Coating," Materials Transactions, vol. 49, pp. 365-371, 2008.

[26] H. Tsutsumi, M. Niinomi, M. Nakai, T. Gozawa, T. Akahori, K. Saito, R. Tu, T. Goto, "Fabrication of Hydroxyapatite Film on Ti-29Nb-13Ta-4.6Zr Using a MOCVD Technique," Materials Transactions, vol. 51, pp. 2277-2283, 2010. 
[27] S.J. Li, M. Niinomi, T. Akahori, T. Kasuga, R. Yang, Y.L. Hao, "Fatigue characteristics of bioactive glass-ceramic-coated Ti-29Nb-13Ta-4.6Zr for biomedical application," Biomaterials, vol. 25, no. 17, pp. 3369-3378, 2004.

[28] M. Nakai, M. Niinomi, T. Akahori, N. Ohtsu, H. Nishimura, H. Toda, H. Toda, H. Fukui, M. Ogawa, "Surface hardening of biomedical Ti-29Nb-13Ta-4.6Zr and Ti-6Al-4V ELI by gas nitriding," Materials Science and Engineering: A, vol. 486, no. 1-2, pp. 193-201, 2008.

[29] T. Niinomi, M. Nakai, H. Nishimura, Y. Takei, H. Fukui, M. Ogawa, "Wear and Mechanical Properties, and Cell Viability of Gas-Nitrided Beta-Type Ti-Nb-Ta-Zr System Alloy for Biomedical Applications," Materials Transactions, vol. 49, no. 1, pp. 166-174, 2008.

[30] C.H. Ng, C.W. Chan, H.C. Man, D. Waugh, J. Lawrence, "Modifications of Surface Properties of Beta Ti by Laser Surface Treatment," in Laser Materials Processing Conference, 34th International Congress on Applications of Laser \& Electro-optics (ICALEO), Atlanta, USA, 2015.

[31] W. Shi, H. Dong, T. Bell, "Tribological behaviour and microscopic wear mechanisms of UHMWPE sliding against thermal oxidation-treated Ti6AI4V," Materials Science and Engineering: A, vol. 291, no. 1-2, pp. 27-36, 2000.

[32] J. Archard, "Contact and Rubbing of Flat Surfaces," Journal of Applied Physics, vol. 24, no. 8, pp. 981-988, 1953.

[33] ASTM Standard G5-94, "Test Method for Making Potentiostatic and Potentiodynamic Anodic Polarization Measurements," ASTM Standards, Philadelphia, PA, USA., 2004.

[34] H. Mohseni, P. Nandwana, A. Tsoi, T.W. Scharf, "In situ nitrided titanium alloys: Microstructural evolution during solidification and wear," Acta Materialia, vol. 83, pp. 61-74, 2015.

[35] E.C. Santos, M. Morita, M. Shiomi, Kozo Osakada, M. Takahashi, "Laser gas nitriding of pure titanium using CW and pulsed Nd:YAG lasers," Surface and Coatings Technology, vol. 201, no. 3-4, pp. 1635-1642, 2006.

[36] T. Röstlund, B. Albrektsson, T. Abrektsson, H. McKellop, "Wear of ion-implanted pure titanium against UHMWPE," Biomaterials, vol. 10, no. 3, pp. 176-181, 1989.

[37] H. Dong, W. Shi, T. Bell, "Potential of improving tribological performance of UHMWPE by engineering the Ti6Al4V counterfaces,” Wear, Vols. 225-229, pp. 146-153, 1999.

[38] D. Xiong, Y. Gao, Y. Jin, "Friction and wear properties of UHMWPE against ion implanted titanium alloy," Surface \& Coatings Technology, vol. 201, pp. 6847-6850, 2007.

[39] D. Xiong, Y. Yang, Y. Deng, "Bio-tribological properties of UHMWPE against surface modified titanium alloys," Surface \& Coatings Technology, vol. 228, pp. S442-S445, 2013.

[40] J. Lima, S.R. Sousa, A. Ferreira, M.A. Barbosa, "Interactions between calcium, phosphate, and albumin on the surface of titanium," Journal of Biomedical Materials Research, vol. 55, no. 1, pp. 45-53, 2001. 
[41] N.T.C. Oliveira, E.A. Ferreira, L.T. Duarte, N. Bocchi, "Corrosion resistance of anodic oxides on the Ti-50Zr and Ti-13Nb-13Zr alloys," Electrochimica Acta, vol. 51, no. 10, pp. 2068-2075, 2006.

[42] S.Y. Yu, J.R. Scully, "Corrosion and passivity of Ti-13\%Nb-13\%Zr in comparison to other biomedical implant alloys," Corrosion, vol. 53, pp. 965-976, 1997.

[43] I. Cvijović-Alagić, Z. Cvijović, J. Bajat, M. Rakin, "Composition and processing effects on the electrochemical characteristics of biomedical titanium alloys," Corrosion Science, vol. 83, pp. 245-254, 2014.

[44] G.V.S. Nageswara Rao, M. Hanumantha Rao, B.V. Appa Rao, P.K. Sagar, "Electrochemical Characterization of Biomedical Titanium alloy Ti-35Nb-7Zr-5Ta," International Journal of Advanced Engineering Technology, vol. 3, no. 1, pp. 217-222, 2012.

[45] N.C. Saha, H.G. Tompkins, "Titanium nitride oxidation chemistry: An x-ray photoelectron spectroscopy study. Journal of Applied Physics," Journal of Applied Physics, vol. 72, no. 7, pp. 3072-3079, 1992.

[46] P. Schaaf, "Laser nitriding of metals," Progress in Materials Science, vol. 47, no. 1, pp. 1-161, 2002.

[47] Endo, K., Sachedeva, R., Araki, Y., Ohno, H., "Effects of titanium nitride coatings on surface and corrosion characteristics of NiTi alloy," Dental Materials Journal, vol. 14, no. 2, pp. 228-389, 1994.

[48] Liu, X., Chu, P.K., Ding, C. , "Surface modification of titanium, titanium alloys and related materials for biomedical applications," Materials Science and Engineering: R: Reports, vol. 47, no. 3-4, p. 49-121, 2004. 


\section{Figure Captions}

Table 1 - Summary of results in the preliminary study [30]

Table 2 - Chemical composition of the TNZT material (wt\%) (American Element, USA)

Table 3 - Composition of Hanks' solution

Table 4 - Surface roughness parameters of the untreated and laser-treated surfaces (extracted from the 3D profile images in Figure 6)

Table 5 - Open-circuit potential $\left(E_{\text {corr }}\right)$ and corrosion current density $\left(i_{c o r r}\right)$ of the untreated and lasertreated surfaces (extracted from the polarisation curves in Figure 7).

Table 6 - XPS compositional measurements (at\%) for the untreated and laser-treated outermost surface layers

Table 7 - Summary of different oxides in the untreated and laser-treated outermost surface layers

Figure 1 - Images of the untreated (right) and laser-treated (left) surfaces obtained from the preliminary study [30]

Figure 2 - Schematic diagram of the laser experiment set-up.

Figure 3 - SEM cross-section image of the laser-treated TNZT surface.

Figure 4 - The GI-XRD patterns for the untreated and laser-treated surfaces.

Figure 5 - Calculated wear factors from the sliding contacts of UHMWPE pin against TNZT plate with or without laser surface treatment.

Figure 6 - 3-D surface profiles for the (a) untreated and (b) laser-treated TNZT plate surfaces after wear tests in Hanks' solution at room temperature.

Figure 7 - Polarization curves for the untreated and laser-treated TNZT surfaces in Hanks' solution at $37^{\circ} \mathrm{C}$.

Figure 8 - XPS survey scan spectra for the (a) untreated and (b) laser-treated surfaces.

Figure 9 - XPS narrow scan spectra of (a-b) Ti 2p, (c-d) Nb 3d, (e-f) Zr 3d, and (g-h) Ta $4 f$ at the outermost oxide layer (without sputter cleaning) or 0 A depth for the untreated and laser-treated surfaces respectively. 
Table 1 - Summary of results in the preliminary study [30]

\begin{tabular}{llcc}
\hline \multicolumn{1}{c}{ Measurement Methods } & \multicolumn{1}{c}{ Measured Parameters } & Untreated & Laser-treated \\
\hline \multirow{2}{*}{ 3-D profile measurement } & Arithmetic mean deviation, $\mathrm{R}_{\mathrm{a}}(\mathrm{nm})$ & 142.68 & 188.74 \\
& Maximum height, $\mathrm{R}_{\mathrm{z}}(\mu \mathrm{m})$ & 2.99 & 3.38 \\
\hline Nano-indentation test & Nano-hardness, $\mathrm{HN}(\mathrm{GPa})$ & 4.81 & 14.35 \\
& Reduced Young's modulus Er $(\mathrm{GPa})$ & 63.87 & 171.24 \\
\hline Contact angle measurement & Distilled water & $66.16 \pm 4.14^{\circ}$ & $54.55 \pm 2.85^{\circ}$ \\
\hline
\end{tabular}

Table 2 - Chemical composition of the TNZT material (wt\%) (American Element, USA)

\begin{tabular}{ccccccccccc}
\hline Composition & $\mathrm{Ti}$ & $\mathrm{Nb}$ & $\mathrm{Zr}$ & $\mathrm{Ta}$ & $\mathrm{Ca}$ & $\mathrm{Mg}$ & $\mathrm{Fe}$ & $\mathrm{Mn}$ & $\mathrm{Si}$ & $\mathrm{Zn}$ \\
\hline wt\% & 51.7 & 35.3 & 7.3 & 5.7 & 0.0023 & 0.0015 & 0.027 & 0.0018 & 0.002 & 0.0006 \\
\hline
\end{tabular}

Table 3 - Composition of Hanks' solution

\begin{tabular}{lc}
\hline \multicolumn{1}{c}{ Component } & Concentration (g/l) \\
\hline Sodium Chloride & 8 \\
Potassium Chloride & 0.4 \\
Potassium Phosphate, monobasic & 0.06 \\
Glucose & 1 \\
Phenol Red, Na salt & 0.01 \\
Sodium Phosphate, dibasic & 0.048 \\
Sodium Bicarbonate & 0.35 \\
\hline
\end{tabular}

Table 4 - Surface roughness parameters of the untreated and laser-treated surfaces (extracted from the 3D profile images in Figure 6)

\begin{tabular}{lllll}
\hline & $\mathrm{R}_{\mathrm{a}}(\mathrm{nm})$ & $\mathrm{R}_{\mathrm{q}}(\mathrm{nm})$ & $\mathrm{R}_{\mathrm{z}}(\mathrm{nm})$ & $\mathrm{R}_{\mathrm{t}}(\mathrm{nm})$ \\
\hline Untreated & 304.84 & 412.23 & 7.62 & 10.27 \\
Laser-treated & 248.82 & 314.49 & 7.54 & 12.81 \\
\hline
\end{tabular}


Table 5 - Open-circuit potential $\left(E_{\text {corr }}\right)$ and corrosion current density $\left(i_{\text {corr }}\right)$ of the untreated and lasertreated surfaces (extracted from the polarisation curves in Figure 7).

\begin{tabular}{lcc}
\hline & Untreated & Treated \\
\hline$E_{\text {corr }}$ & $-590 \mathrm{mV}$ & $-431 \mathrm{mV}$ \\
$i_{\text {corr }}$ & $15.07 \mu \mathrm{A} / \mathrm{cm}^{2}$ & $0.28 \mu \mathrm{A} / \mathrm{cm}^{2}$ \\
\hline
\end{tabular}

Table 6 - XPS compositional measurements (at\%) for the untreated and laser-treated outermost surface layers

\begin{tabular}{lccccccccc}
\hline Element & Ti 2p & Nb 3d & Zr 3d & Zn 2p3/2 & Ta 4f & O 1s & C 1s & N 1s & Others \\
\hline Untreated & $7.59 \%$ & $3.89 \%$ & $0.85 \%$ & --- & $0.14 \%$ & $41.81 \%$ & $37.79 \%$ & $1.77 \%$ & $6.17 \%$ \\
Laser-treated & $10.43 \%$ & $2.35 \%$ & $0.55 \%$ & $0.46 \%$ & $0.11 \%$ & $48.71 \%$ & $29.38 \%$ & $1.81 \%$ & $6.20 \%$ \\
\hline
\end{tabular}

Table 7 - Summary of different oxides in the untreated and laser-treated outermost surface layers

\begin{tabular}{ccc}
\hline Alloying Elements & Untreated & Laser-treated \\
\hline $\mathrm{Ti} 2 \mathrm{p}$ & $\mathrm{Ti}, \mathrm{TiO}_{\mathrm{Ti}} \mathrm{Oi}_{3} \mathrm{TiO}_{2}$, & $\mathrm{TiO}_{2}$ \\
$\mathrm{Nb} 3 \mathrm{~d}$ & $\mathrm{Nb}, \mathrm{NbO}, \mathrm{NbO}_{2}, \mathrm{Nb}_{2} \mathrm{O}_{5}$ & $\mathrm{Nb}_{2} \mathrm{O}_{5}$ \\
$\mathrm{Zr} 3 \mathrm{~d}$ & $\mathrm{ZrO}_{2}$ & $\mathrm{ZrO}_{2}$ \\
$\mathrm{Ta}$ 4f & $\mathrm{Ta}_{2} \mathrm{O}_{5}$ & $\mathrm{Ta}_{2} \mathrm{O}_{5}$ \\
\hline
\end{tabular}




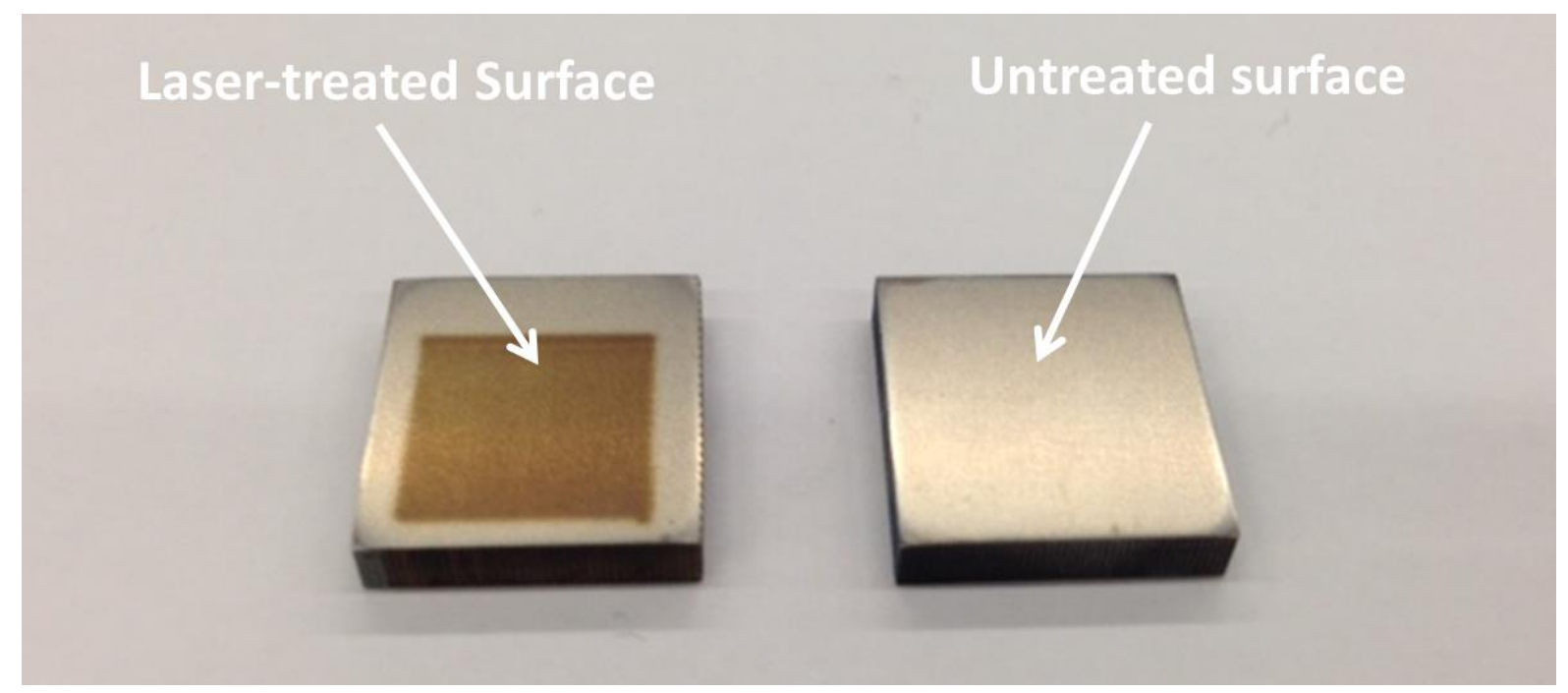

Figure 1 -Images of the untreated (right) and laser-treated (left) surfaces obtained from the preliminary study [30]

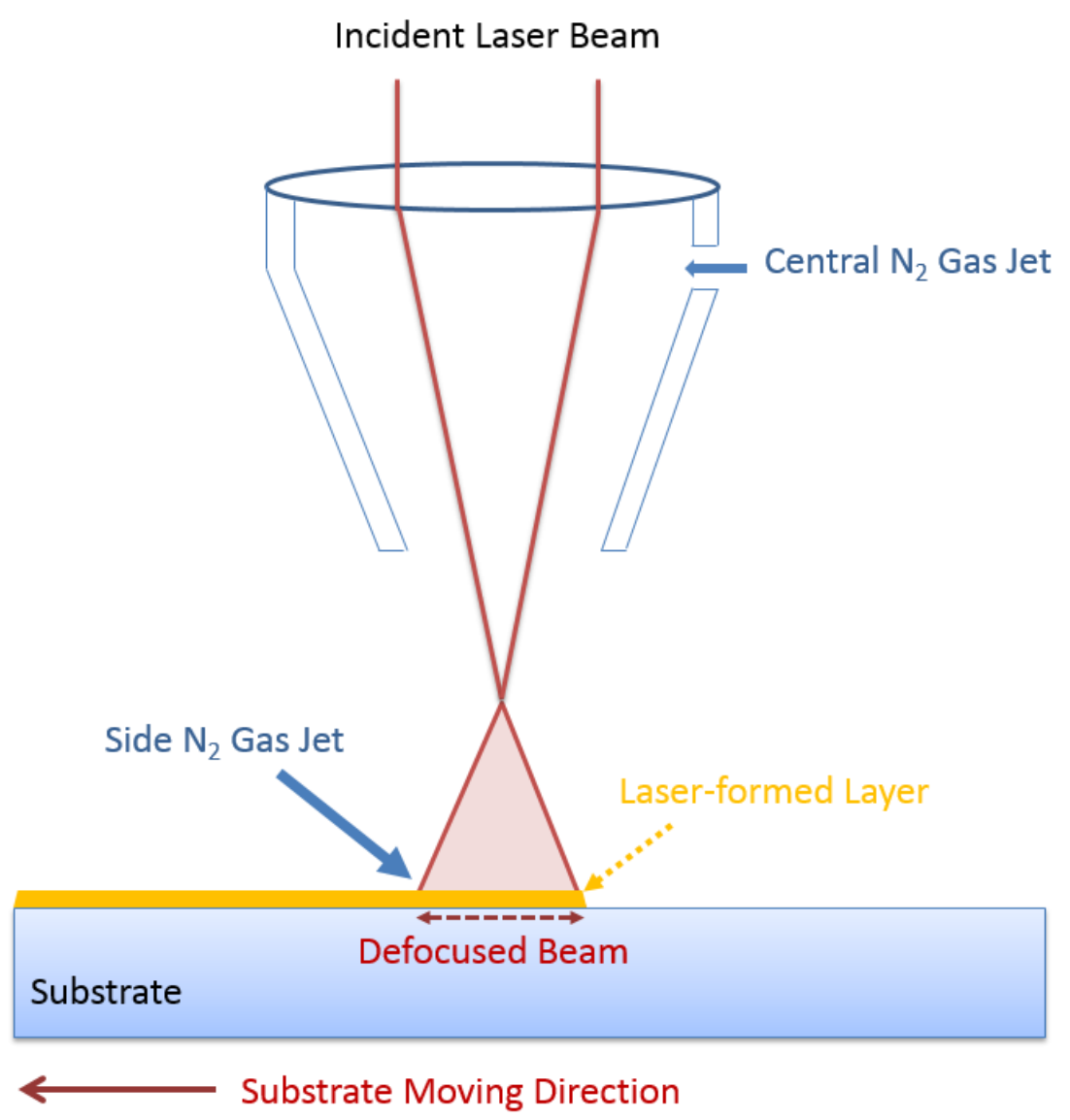

Figure 2 - Schematic diagram of the laser experiment set-up. The laser beam was defocused and the substrate was moved from right to left while the laser head was kept stationary. $N_{2}$ gas was delivered to the laser-irradiated area via central and side gas jets. With delicate control of laser energy input and $\mathrm{N}_{2}$ atmosphere, a smooth golden-yellowish layer can be created on the TNZT surface without causing surface melting. 


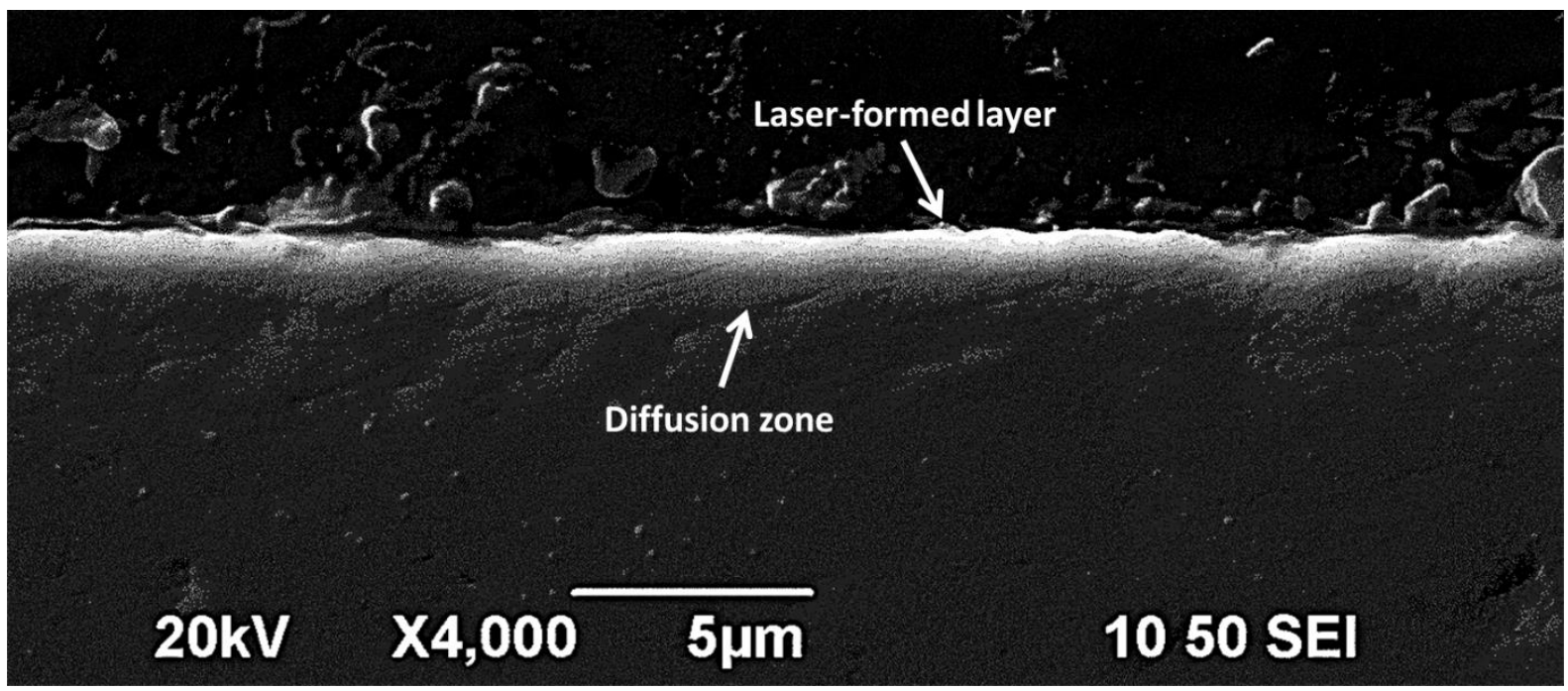

Figure 3 - SEM cross-section image of the laser-treated TNZT surface. A smooth and uniform laserformed layer as well as a diffusion zone (beneath the surface layer) can be observed in the substrate. No obvious defect was found in the layer.

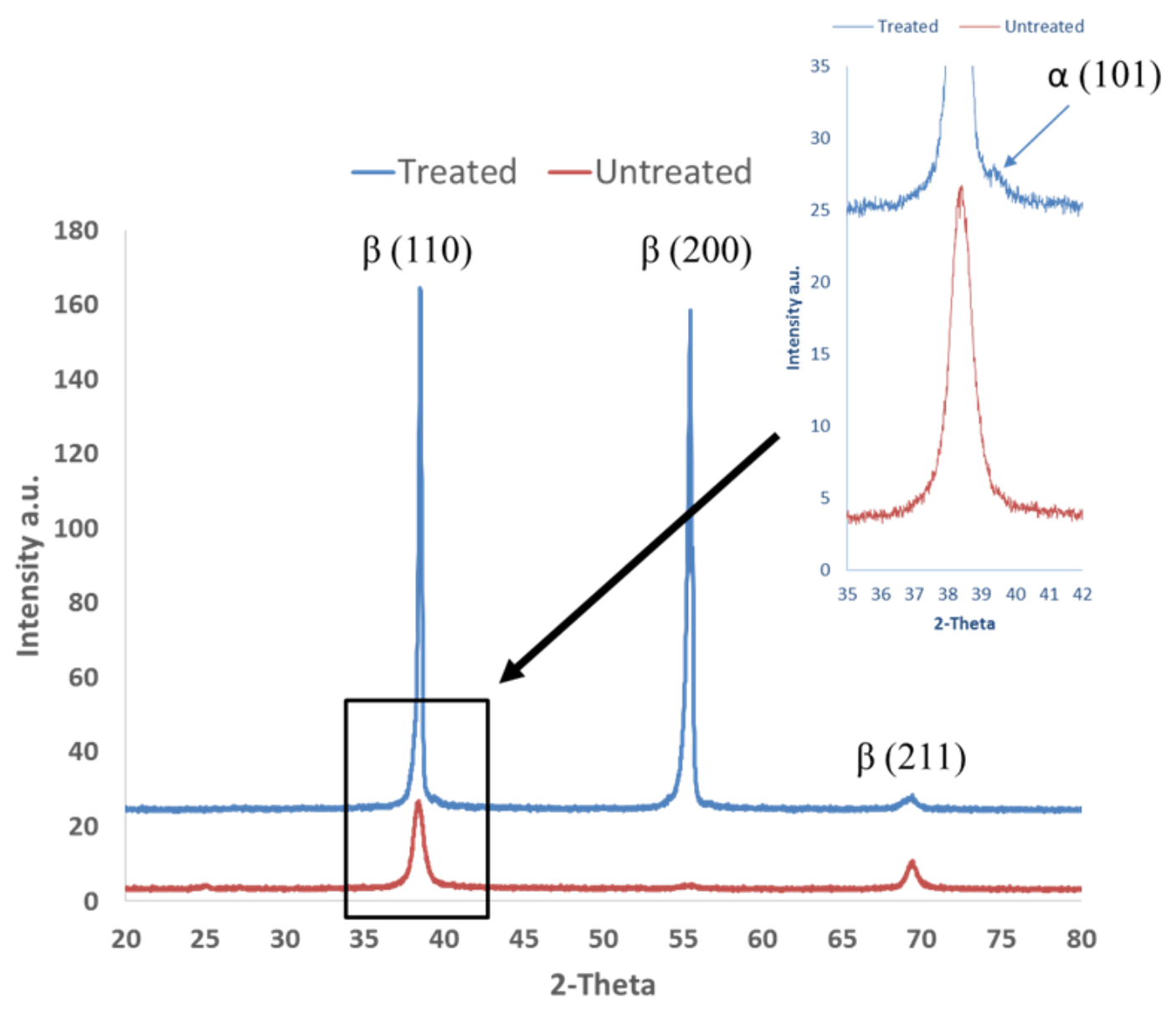

Figure 4 - The GI-XRD patterns for the untreated and laser-treated surfaces. The small peak at (101) in the inset shows the presence of alpha phase in the surface structure of the laser-formed layer. 


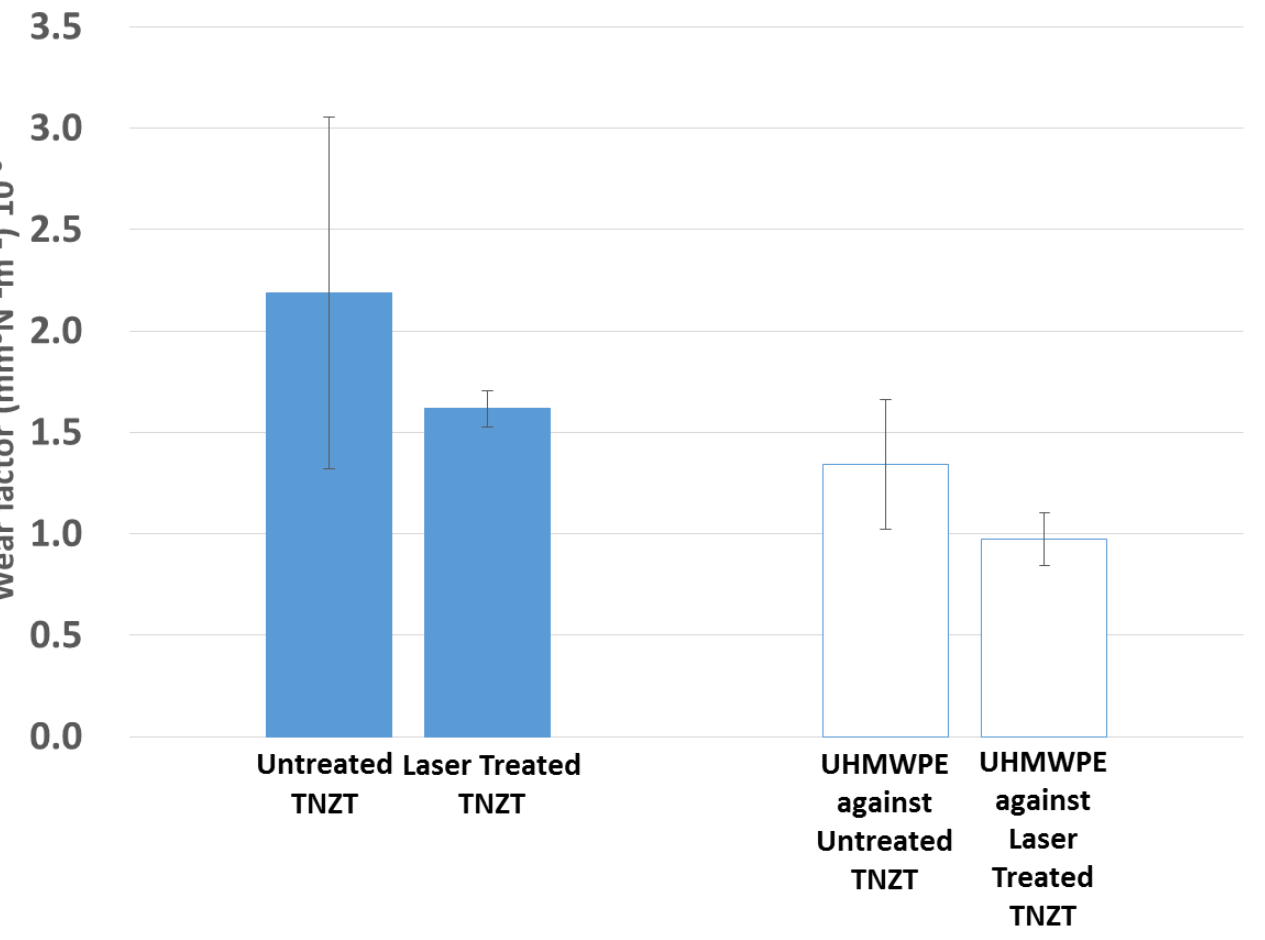

Figure 5 - Calculated wear factors from the sliding contacts of UHMWPE pin against TNZT plate with or without laser surface treatment. The filled bars represent the wear factors for the untreated (left) and laser-treated TNZT (right); the empty bars represent the wear factors for UHMWPE counterface against the untreated (left) and laser-treated TNZT (right). 


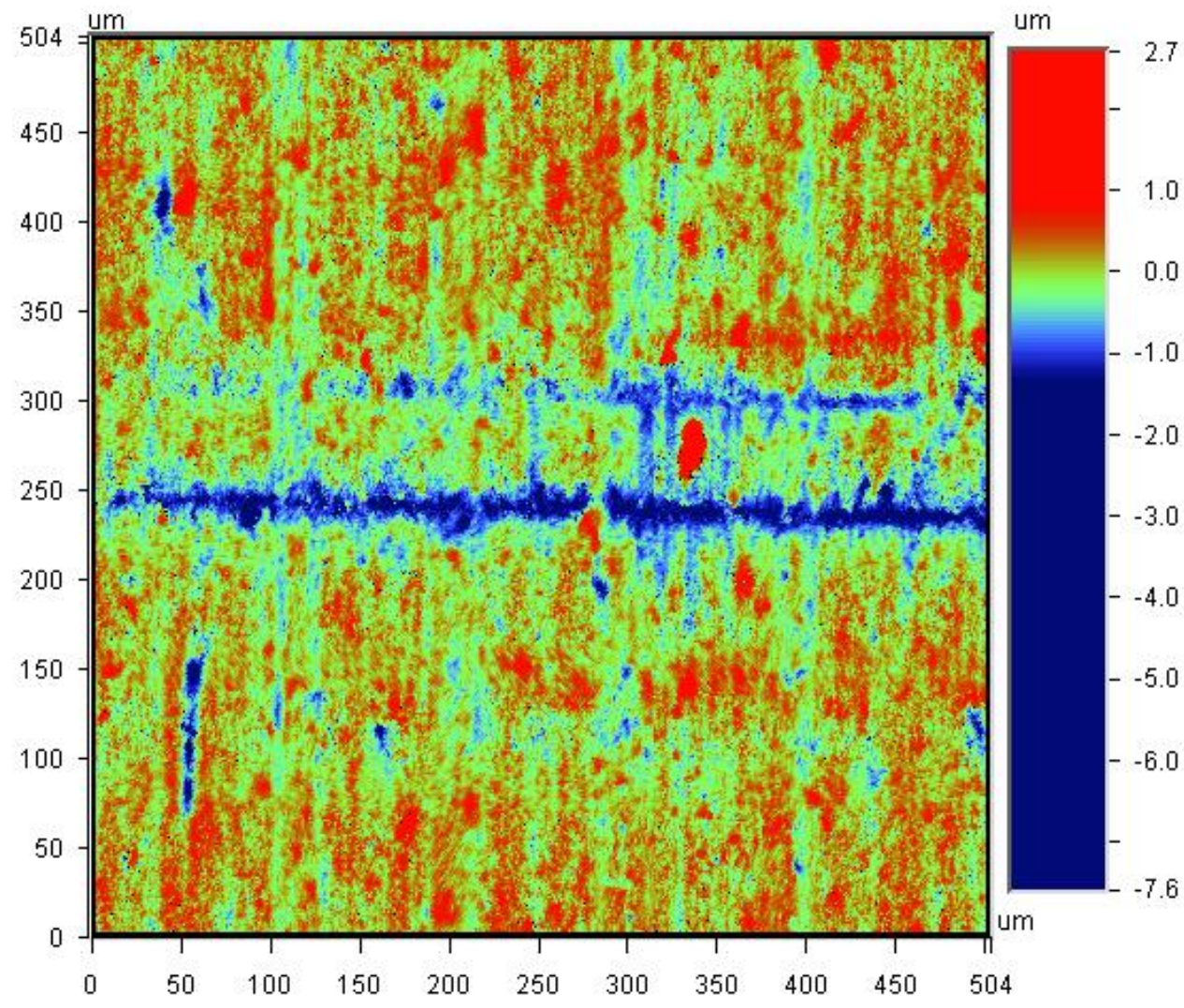

(a) Untreated surface

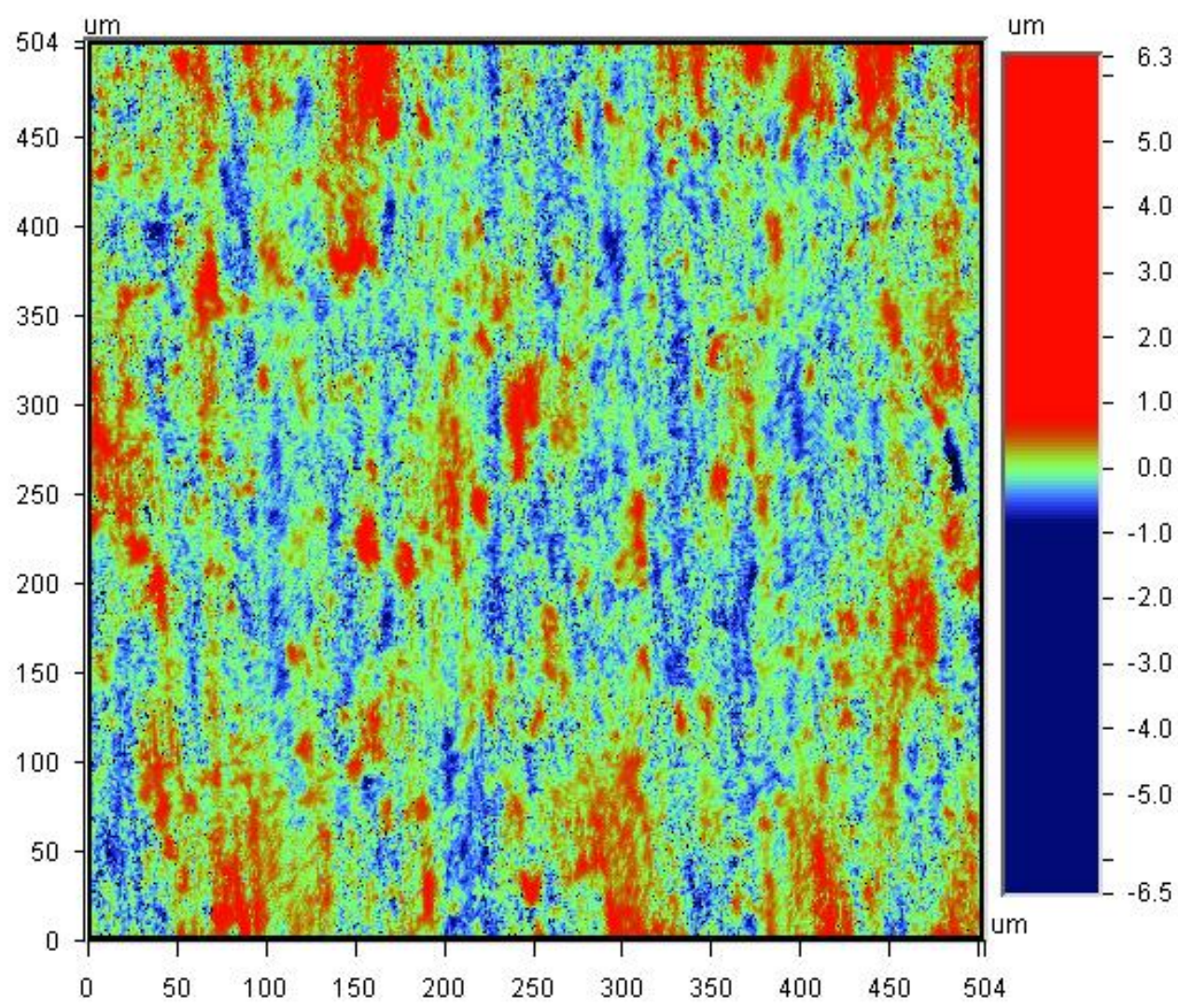

(b) Laser-treated surface 


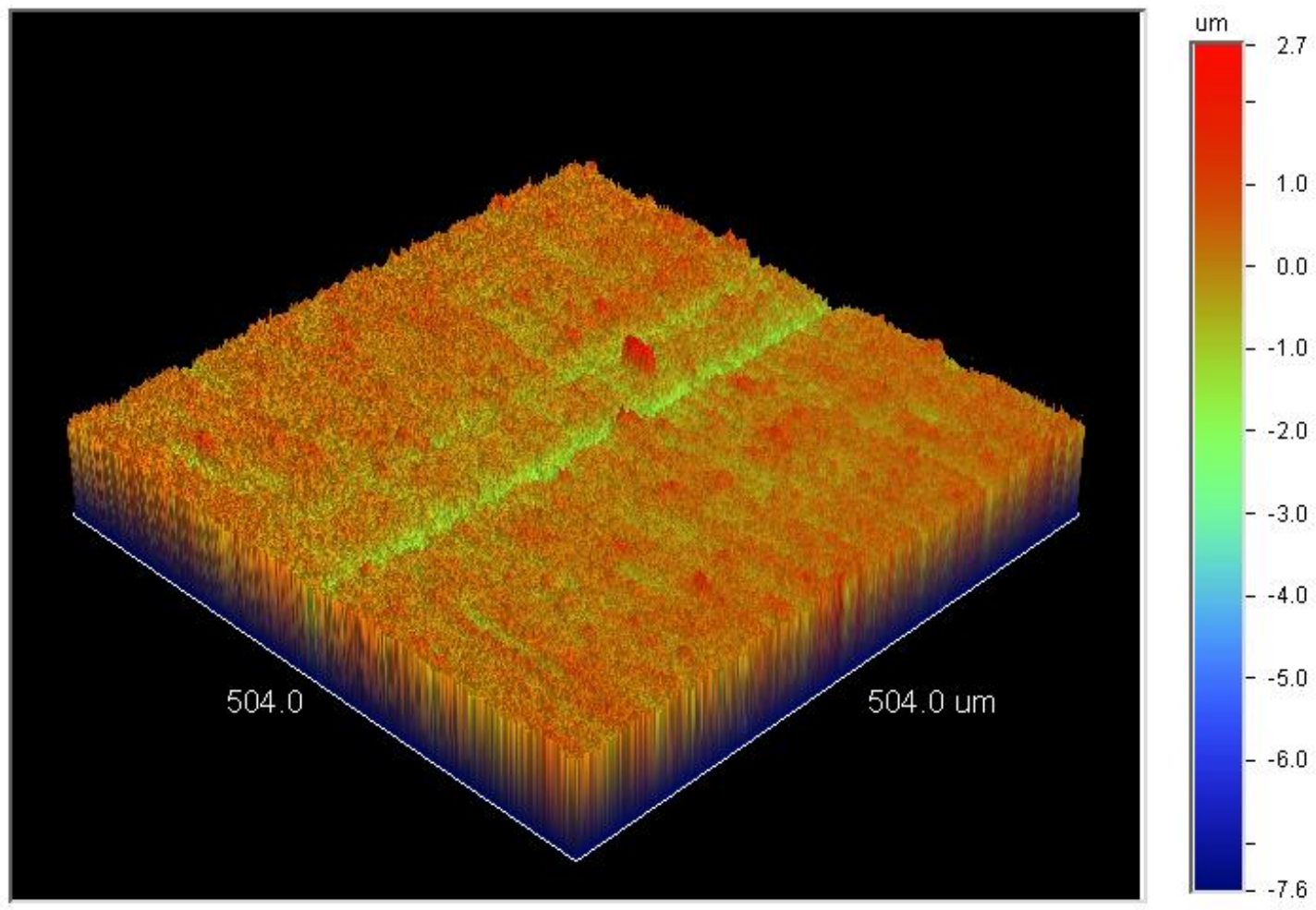

(a) Untreated surface

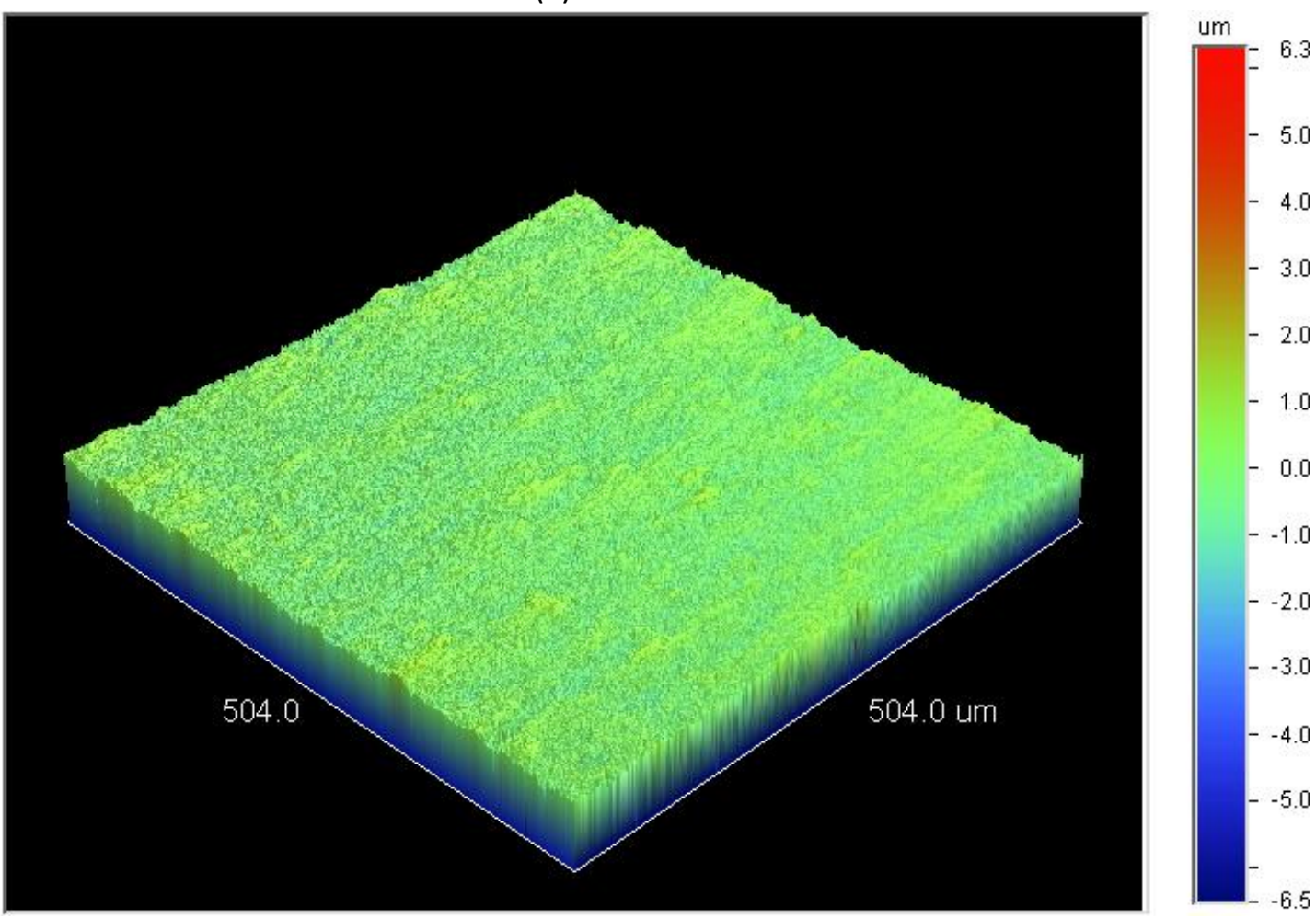

(b) Laser-treated surface

Figure 6 - 3-D surface profiles for the (a) untreated and (b) laser-treated TNZT plate surfaces after wear tests in Hanks' solution at room temperature. Clear wear grooves were found in the middle of untreated TNZT plate surface while the laser-treated TNZT plate surface showed a randomly distributed topography after testing. 


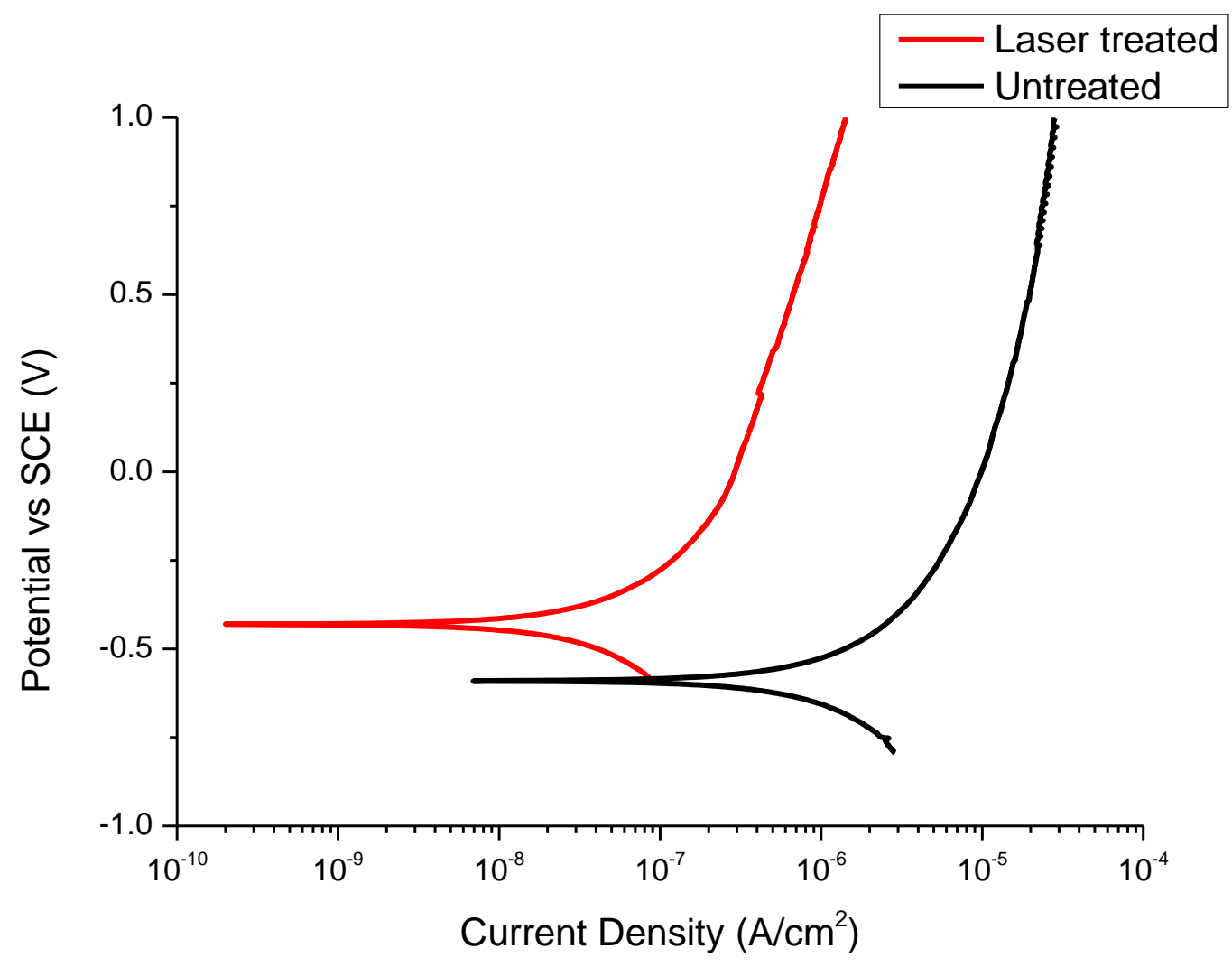

Figure 7 - Polarization curves for the untreated (black) and laser-treated (red) TNZT surfaces in Hanks' solution at $37^{\circ} \mathrm{C}$. The laser-treated surface showed higher corrosion resistance than the untreated as evidenced by the higher OCP and lower current density values. 


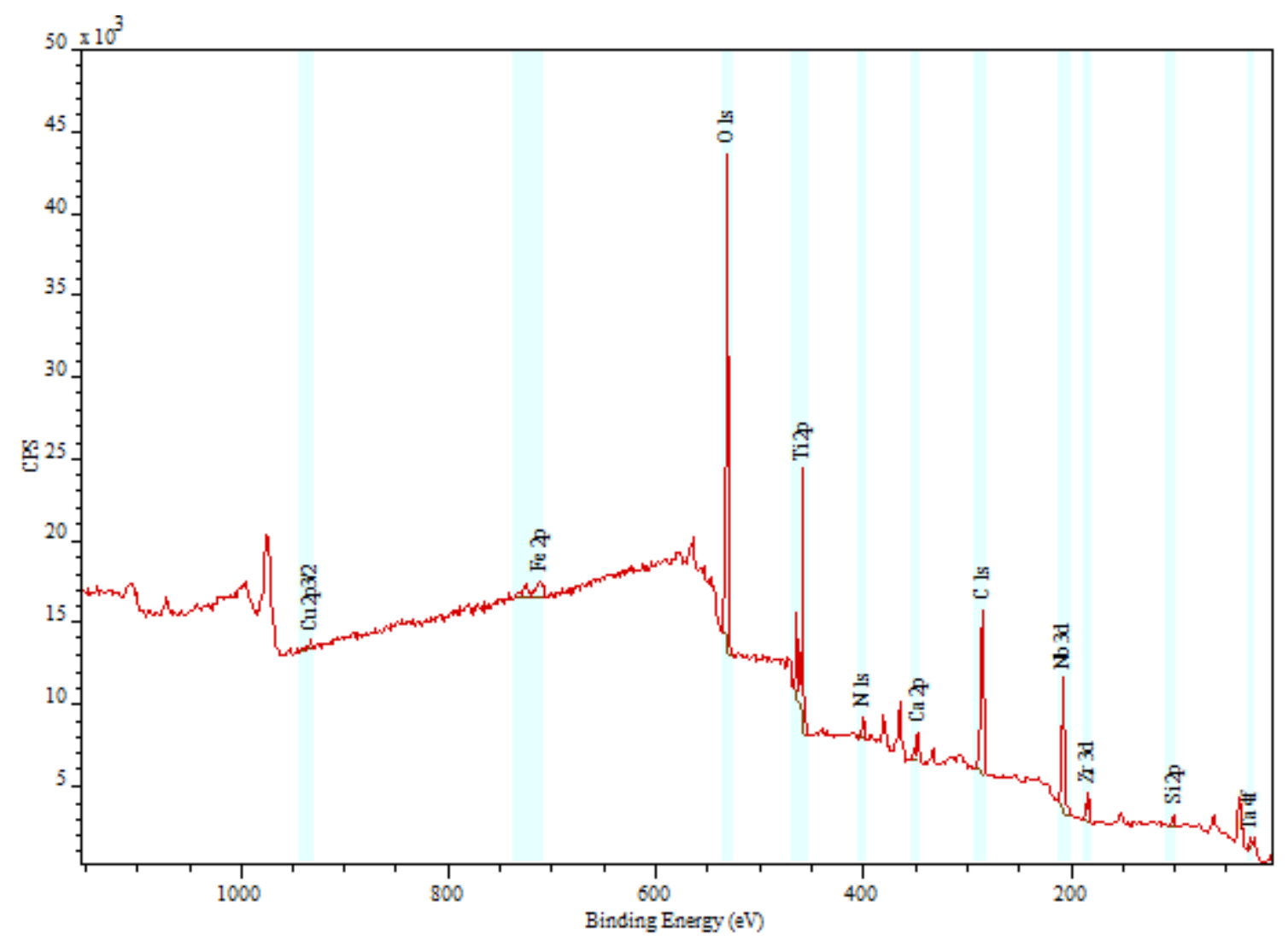

(a) Untreated surface

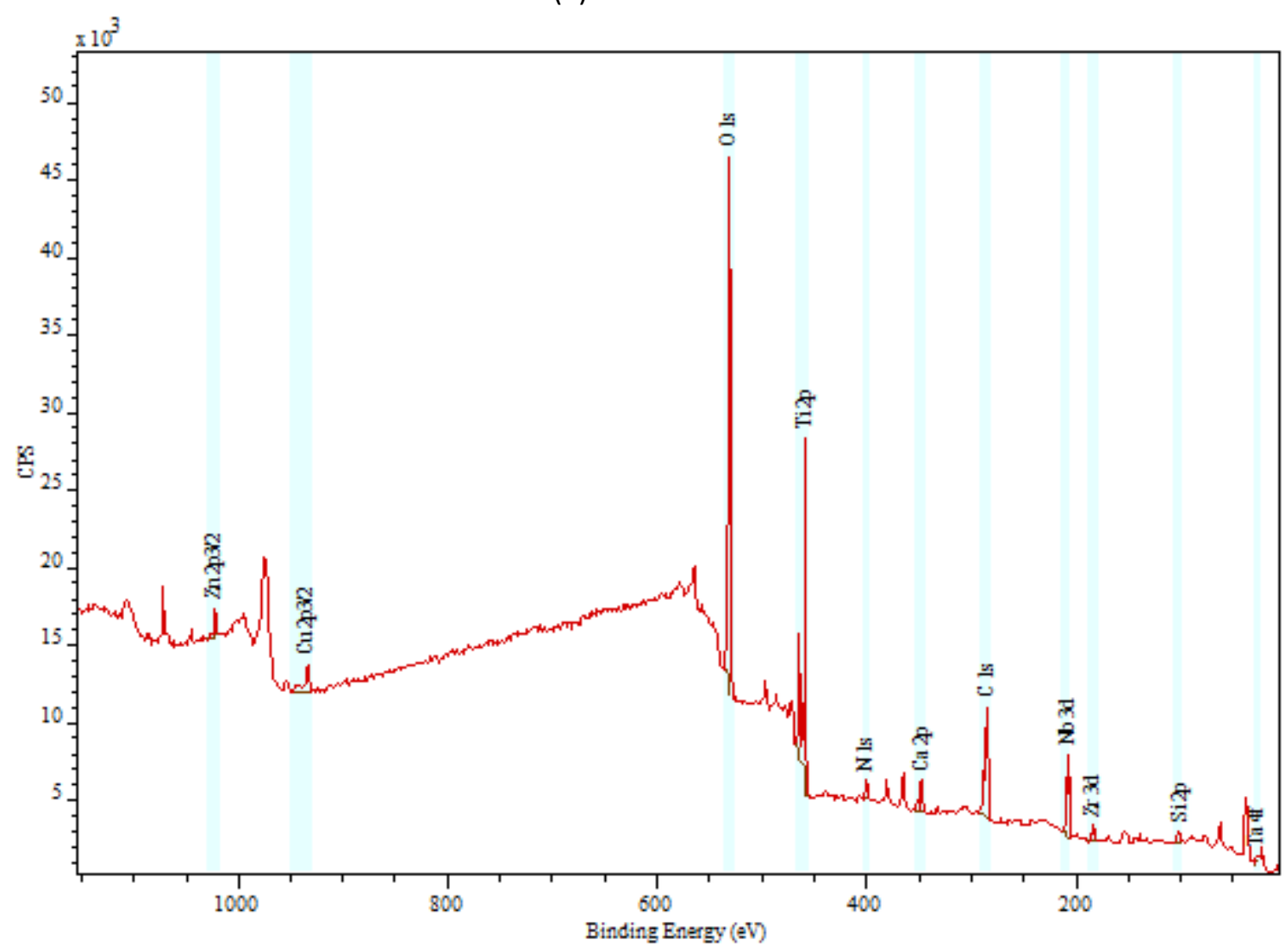

(b) Laser-treated surface

Figure 8 - XPS survey scan spectra for the (a) untreated and (b) laser-treated surfaces. 
Ti $2 p$ Untreated

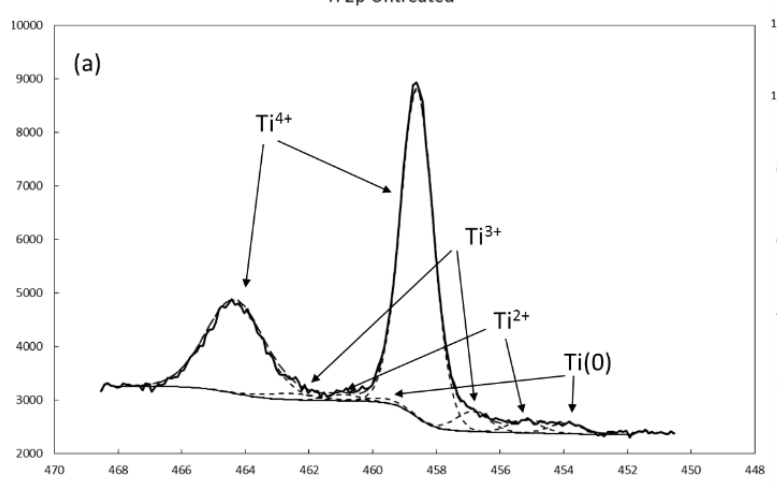

$\mathrm{Nb}$ 3d Unteate
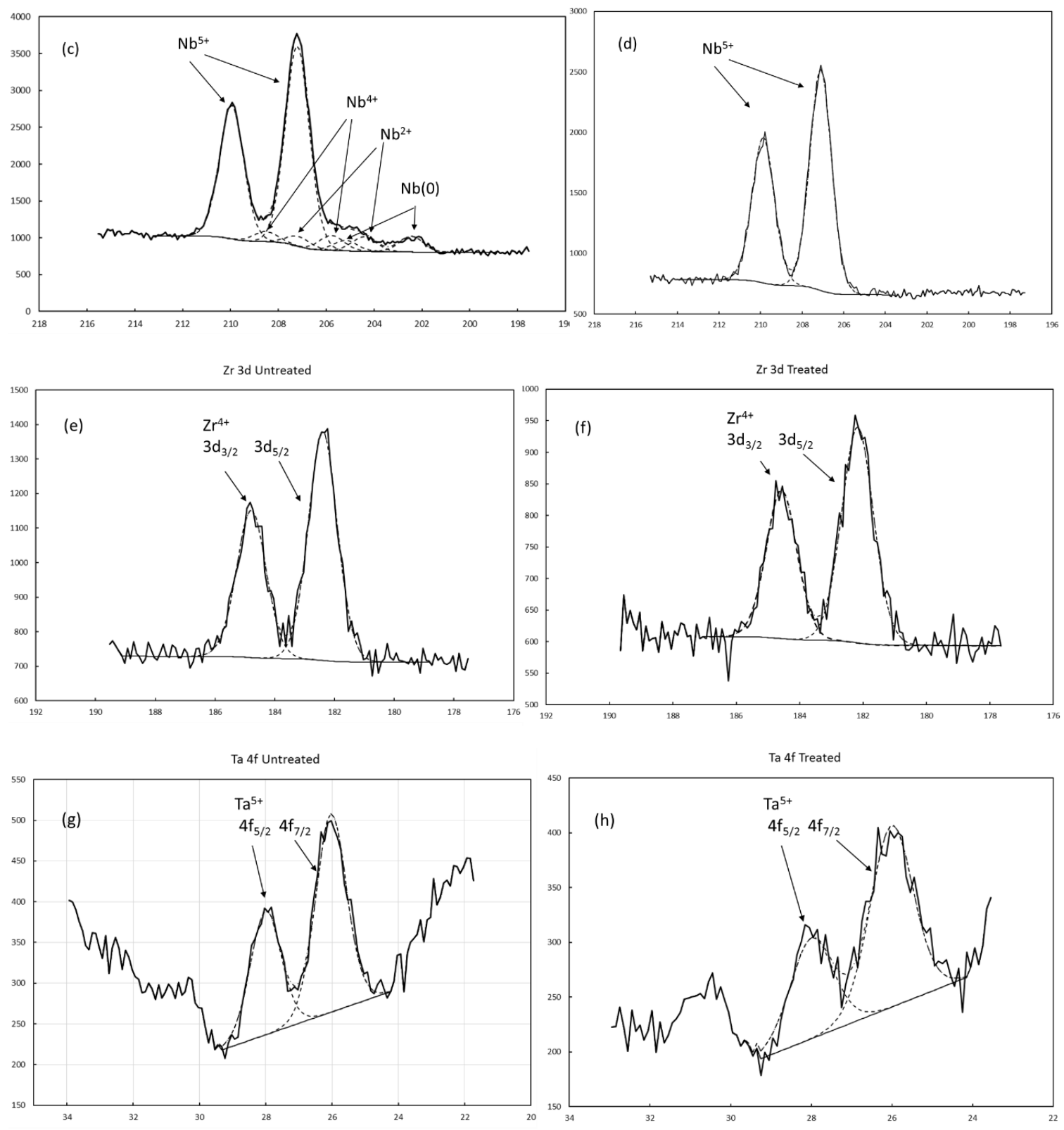

Figure 9 - XPS narrow scan spectra of (a-b) Ti 2p, (c-d) Nb 3d, (e-f) Zr 3d, and (g-h) Ta $4 f$ at the outermost oxide layer (without sputter cleaning) or 0 A depth for the untreated and laser-treated surfaces respectively. The metals on the laser-treated surface were completely oxidised whereas some sub-oxides and metallic species were present on the untreated surface. 